\title{
Developing a Scoring System to Evaluate the Level of Smartness in Commercial Buildings: A Case of Sri Lanka
}

\author{
Randima Nirmal Gunatilaka ${ }^{1}$, Fathima Nishara Abdeen ${ }^{2, *(D)}$ and Samad M. E. Sepasgozar ${ }^{2}$ (D) \\ 1 Eutech Cybernetic, Colombo 00700, Sri Lanka; randimanirmal94@gmail.com \\ 2 School of Built Environment, Faculty of Arts, Design and Architecture, University of New South Wales, \\ Sydney 1466, Australia; Sepas@unsw.edu.au \\ * Correspondence: n.abdeen@unsw.edu.au
}

Citation: Gunatilaka, R.N.; Abdeen, F.N.; Sepasgozar, S.M.E. Developing a Scoring System to Evaluate the Level of Smartness in Commercial Buildings: A Case of Sri Lanka. Buildings 2021, 11, 644. https:// doi.org/10.3390/buildings11120644

Academic Editor: Patrick Dallasega

Received: 26 October 2021

Accepted: 9 December 2021

Published: 13 December 2021

Publisher's Note: MDPI stays neutral with regard to jurisdictional claims in published maps and institutional affiliations.

Copyright: (c) 2021 by the authors. Licensee MDPI, Basel, Switzerland. This article is an open access article distributed under the terms and conditions of the Creative Commons Attribution (CC BY) license (https:// creativecommons.org/licenses/by/ $4.0 /)$.
Abstract: Smart buildings (SBs) are developed in many different ways and are self-proclaimed smart. There are a great number of publications introducing smart systems using a wider range of tools and sensors. However, the level of smartness, functions of the smart system, and the usefulness of the system are not the same, which may give a wrong impression to clients or potential buyers of a building. Developing a scoring system that enables determining the overall smartness of a building is necessary. Despite the necessity, there is a dearth of studies in this area. Hence, the purpose of this study is to develop a scoring system to evaluate the level of smartness of Sri Lankan commercial buildings. Thus, initially, smart criteria were identified, defined, and categorized through a literature survey. Subsequently, 35 experts in the commercial building sector were interviewed. Finally, the relative importance of the smart criteria was derived through the AHP technique, and accordingly, a scoring system was developed. The study identified six main criteria to evaluate the smartness of buildings in the scoring system. The automation criterion with the highest relative weight was concluded to be the dominant criterion (45.59\%) in the scoring system. Communication and data sharing were placed at second with a relative weight of $18.76 \%$ and indicates the importance given by the study findings in establishing the backbones of SBs. Occupants' comfort, energy management, occupants' health and safety, and sustainability criterion were ranked third, fourth, fifth, and sixth within the scoring system. This study is one of the first to investigate in detail the contribution of both soft and hard services of a facility in determining the overall smartness of a building. Property developers in the commercial building sector can benefit from this study by recognizing the necessary criteria to be embedded in their SB development projects in order to attract more tenants and customers.

Keywords: smart buildings; commercial buildings; automation; IoT sensors; analytical hierarchy process

\section{Introduction}

The worldwide commercial real estate industry is worth over 32.6 trillion USD as of 2020, up from 30.3 trillion USD in 2019 [1]. The highest market size has been reported in Europe, the Middle East, and Africa (EMEA), which was estimated at close to 10.3 trillion USD, just marginally higher than the Asia Pacific and North America regions. Within the Sri Lankan context, a study conducted by the Research Intelligence Unit (RIU) concluded that the country has 1.9 million square feet of Grade A commercial space, the top tier in the country's market [2]. According to Lugoda [2], the commercial facilities comprised many key attributes similar to high-end construction and interior finishes, contemporary architecture design, state-of-the-art mechanical infrastructure and applications, and various property functions and facilities. Through advanced IoT sensors, a smart commercial building can integrate the information generated from the above building functions, systems, and subsystems to automate and enhance building performance [3]. Smart buildings (SBs) 
are known as an overall solution for many requirements raised by concerned individuals, owners, managers, and tenants in a building [4].

SBs provide an avenue for landlords to obtain a more precise picture of how the building is used, assist the management to be more efficient (keeping the building in perfect condition), and provide tenants with a more comfortable and productive environment [4]. Hence, a typical SB contains numerous interconnected technology systems that work together and adapt to changing needs, which benefits users, owners, and the environment [5]. While in a common building these systems are installed and operate independently, in SBs they are planned and coordinated together in a single consolidated project [6]. SBs, therefore, encompass many features to ensure the performance of a building, such as energy management, maintenance management, indoor comfort, space management, traffic management, security management, etc. [5]. However, SBs are often confused with zero energy buildings or passive buildings, which are not the same as SBs [6]. Zero energy buildings or passive buildings more often address sustainability features of a building. Moreover, today's buildings are designed in a variety of ways and are self-described as smart [7]. For a building to be labeled "smart", there is no certification or rating system in place. Further, the existing building evaluation tools mostly focus on a specific criterion, mainly environmental aspects [7], henceforth, the applicability of such a criterion in determining the level of smartness of a building is questioned. Therefore, developing a scoring system that would enable determination of the overall smartness of a building is necessary.

Jain [7] had attempted to develop the key criteria yet has given major importance to ICT and building services and has not focused on the Sri Lankan context. The Directive 2010/31/EU and Directive 2012/27/EU (2019) [8] presents a methodology for calculating smart readiness indicators. According to the methodology, the smart readiness of a building or building unit is determined based on the assessment of nine technical domains. Moreover, The Honeywell Smart Building Score ${ }^{\mathrm{TM}}$ has been developed as a framework for the assessment of buildings. It focuses on scoring the assets that make up a building based on three main outcomes: green, safe, and productive [9]. Further, the study of Omar [10] proposed a multi-criteria framework composed of subfactors as a comprehensive tool for the categorization of intelligent buildings. However, these studies derived a set of different indicators and have not been tested to validate the applicability to the Sri Lankan context. A tool for the assessment of green interior decoration in the context of China was proposed by the study of $\mathrm{Wu}$ et al. [11]; however, no focus had been put forward towards SBs other than building comprehensively upon the sustainability aspect, one of the key elements of SBs. As stated by Wang et al. [12], a SB should be able to overcome both intelligence and sustainability concerns by using smart technologies to accomplish the optimum combination of overall comfort and energy efficiency. Therefore, despite the necessity of defining a scoring system for smart commercial building, there is a dearth of studies in this regard in Sri Lanka. Therefore, this study sets out to bridge this gap by addressing the following research questions, which will lead towards creating a scoring system to evaluate the smartness of commercial buildings. The questions refer to what are the criteria for evaluating the smartness of a commercial building and what is the relative importance of these criteria in constructing a smart commercial building is. The questions will be addressed in separate sections following Section 3.

\section{Literature Review}

\subsection{Existing Building Evaluation Schemes}

Carter and Mankoff [13] insisted that designing and evaluating SB applications is a nontrivial matter. Therefore, the study initially investigated the extent to which the existing building evaluation schemes and/or benchmarking schemes have given prominence for smart features for commercial buildings. At the initial stage, building evaluation and/or benchmarking schemes developed in Sri Lanka were studied, and it was found that the GREENSL ${ }^{\circledR}$ rating scheme for the built environment developed by the Green Building Council of Sri Lanka is the only locally developed benchmarking scheme for the built envi- 
ronment. Therefore, extending the review further, green building rating schemes that are widely used in North America, Europe, and Asia, namely, Green Globes, LEED, BREEAM, GRIHA, IGBC system, Green Mark, CASBEE, and Green Star [14] were considered. These building rating schemes are chosen for comparison based on the national requirements in Sri Lanka and the coverage in terms of the number of buildings certified across the globe. Based on the foregoing review, it was understood that the above certification is highly focused on overall life cycle evaluation and ensuring long-term environmental benefits. Even within the sustainability domain, most of the evaluation schemes are criticized for the unequal treatment of the three pillars of sustainability [14]. Further, it is apparent that all the existing building evaluation tools are mostly focused on a specific criterion, mainly environmental aspects [7], henceforth, the applicability of such a criterion in determining the level of smartness of a building is questioned.

\subsection{Existing Scoring Methods}

Seismic risk assessments have consistently seized the attention of researchers in devising scoring methods to estimate the risk to structures [15]. Current literature used various assessment methods to determine the correlation between the building vulnerability parameters and the damage grades for individual buildings [16]. These methods include soft computing techniques such as artificial neural network (ANN)-based models, fuzzylogic-based models, machine-learning-based models, probabilistic-based models, other models such as analytical hierarchy process (AHP), and integrated models [16]. Harirchian et al. [17] propose a new machine-learning-based convolution neural networks method to identify key features of buildings and compute the vulnerability index for seismic action. The use of multi-criteria decision making (MCDM) techniques also seems to be popular in the field in devising assessment methods for seismic risk. Harirchian et al. [18] studied the use of MCDM techniques for seismic vulnerability assessment, specifically to classify the damage index of reinforced concrete buildings. Alam et al. [19] used the AHP to compare vulnerability assessment methodologies to select a proper tool for assessing the seismic risk for a group of buildings. According to Harirchian et al. [18], among MCDM methods, AHP and the technique for order of preference by similarity to ideal solution (TOPSIS) give the best results for seismic vulnerability assessments. However, the use of AHP in devising scoring systems for application in several other fields was apparent, such as for green interior assessments. Particularly, the study of Wu et al. [11] presents an AHP-based assessment system for green interior decoration. The study covers seven basic aspects: energy saving and utilization, water saving and utilization, material saving and utilization, site space saving and utilization, indoor environment quality, green construction management, and operation management. Sepasgozar et al. [20] present a set of identified factors leading to the usage of mixed reality digital twin, and these factors have been used to develop a predictive model to evaluate virtual, augmented, and mixed reality (MR) acceptance by users. Quantity indicators such as path coefficients, factor ranking, Cronbach's alpha, and chi-square test are used in this study. Moreover, the application of ANN with a deep learning structure is emerging in the building sector. Using ANN, authors such as Serrano [21] devised models to ensure that smart buildings adapt to the external environment by learning from their users and monitoring key building parameters (e.g., energy, asset, space).

Extending the review further, several smartness evaluation schemes with a particular focus on the building sector were reviewed to support the research aim. These include the Directive 2010/31/EU and Directive 2012/27 /EU [8], The Honeywell Smart Building Score (HSBS) [9], and the studies of Omar [10], Cardone et al. [22], and Morvaj et al. [23]. The Directive 2010/31/EU and Directive 2012/27/EU [8] present a methodology for deriving a rating for smart readiness for a given building. The methodology is based on nine technical domains (i.e., 1. heating; 2 . cooling; 3 . domestic hot water; 4 . controlled ventilation; 5. lighting; 6. dynamic building envelope; 7. electricity; 8. electric vehicle charging; and 9. monitoring and control). However, given the Sri Lankan phenomenon and being 
an Asian country, the applicability of the directive to the Sri Lankan context is highly questionable. Further, The Honeywell Smart Building Score (HSBS) developed by [9] is based on 15 technology assets with three main impact criteria: green, safe, and productive. Moreover, Omar [10] proves an extensive list of indicators to assess the smartness of intelligent building main evaluation criteria under seven factors (intelligent skins, building automation system (BAS), building management system (BMS), sensors, smart materials, passive design technologies, and renewable resources) and 68 subfactors. Cardone et al. [22] identified an exhaustive list of features for smart cities, including assistance to the people for health care, mobile medical care facilities, help for elders, intelligent control and energy management, automatic traffic control systems, and intelligent building management systems. Morvaj et al. [23] showed another array of key features that include renewable energy sources, energy storage, smart metering, smart devices, building automation, and broadband access. These scoring schemes provide an extensive list of indicators which have not been tested and validated for applicability in Sri Lanka. Hence, given the availability of different scoring systems utilized in different contexts, there is a requirement to develop a set of criteria and a scoring system that would provide an avenue to understand the overall smartness of commercial buildings in Sri Lanka.

\subsection{Criteria to Evaluate Smartness}

In the early 1960s, intelligent buildings were only a mechanistic explanation that reflected the building's potential perspective and creative progress with technological and scientific innovations [24]. However, during the recent decade and since, smart buildings have quickly turned into a fundamental and a key segment of policies in designing and developing many building projects [25]. This will lead to smart growth, sustainable development, and a stronger environment. According to Everett [26], a smart building is a dynamic and responsive architecture that continuously interacts among its four basic elements: places (fabric, structure, and facilities), processes (automation, control, and systems), people (services and users), and management (maintenance and performance) to provide every tenant with productive, cost-effective, and environmentally friendly settings. However, understanding the distinctive and specific criteria that incorporates a smart building is quite challenging since they differ from conventional buildings [6,27].

Hence, initially, the study carried out an extensive literature review to determine the criteria of smart buildings in a more systematic manner. This would enable the study to generate a more robust set of criteria by scanning the existing literature as the lack of consensus between existing studies prevails in terms of defined criteria. The findings of the review are presented in Table 1.

Table 1. Literature review findings: criteria to evaluate SBs.

\begin{tabular}{ccc}
\hline \multicolumn{1}{c}{ Category } & \multicolumn{1}{c}{ Sub-Criteria } & Examples or Cases \\
\hline & \multicolumn{1}{c}{ Intelligent controls and management } & {$[5,23,28]$} \\
\cline { 2 - 3 } 01. Energy management & Energy-efficient procedure development and usage & {$[9,10,28,29]$} \\
\cline { 2 - 3 } & Adaptive energy systems & {$[8,9,30]$} \\
\hline & Energy storage & {$[8,23,31]$} \\
\cline { 2 - 3 } 02. Health and safety & Assistance to people for health care & {$[5,8,10,33]$} \\
\cline { 2 - 3 } & Security and access control & {$[9,34]$} \\
\cline { 2 - 3 } & Emergency response & {$[9,10,35,36]$} \\
\hline
\end{tabular}


Table 1. Cont.

\begin{tabular}{|c|c|c|}
\hline Category & Sub-Criteria & Examples or Cases \\
\hline \multirow{5}{*}{ 03. Building Automation } & Automatic occupants' traffic control & {$[9,10,40]$} \\
\hline & Building management system with intelligent controls & {$[10,41,42]$} \\
\hline & Asset tracking & {$[10,41]$} \\
\hline & Data gathering devices with sensor networks & {$[10,41,42]$} \\
\hline & Remote monitoring & {$[40,43]$} \\
\hline \multirow{6}{*}{ 04. Occupancy comfort } & Indoor air quality & {$[8-10,40]$} \\
\hline & Visual comfort & {$[8-10,40]$} \\
\hline & Acoustic comfort & {$[8,40,42]$} \\
\hline & Thermal comfort & {$[8-10,40]$} \\
\hline & Smart appliances for personalized control & {$[8,10,23]$} \\
\hline & Space utilization and passive design & {$[7,44]$} \\
\hline \multirow{5}{*}{$\begin{array}{l}\text { 05. Communication and data } \\
\text { sharing }\end{array}$} & Cloud-based data sharing and storage & {$[5,45,46]$} \\
\hline & Data protection & {$[5,45,46]$} \\
\hline & Internet of Things & {$[45,47,48]$} \\
\hline & Wireless technologies & {$[45,48]$} \\
\hline & Cyber-physical system & {$[8,10]$} \\
\hline \multirow{5}{*}{ 06. Sustainability features } & Renewable energy source & {$[7,49-51]$} \\
\hline & Material Conservation & {$[10,49,51]$} \\
\hline & Water Conservation & {$[9,10,51,52]$} \\
\hline & Land Conservation & {$[52]$} \\
\hline & Usage of waste management strategies & {$[52,53]$} \\
\hline
\end{tabular}

A brief explanation of the major categories identified in Table 1 is provided below.

\subsubsection{Energy Management}

Building energy management is essential in decreasing electricity consumption and reducing grid strain [32]. According to the authors, building automation and energy management systems play a critical role in lowering energy usage in buildings due to advances in computing and communication technology. Moreover, the use of energy efficiency as a risk management technique has been widely encouraged [54]. Proper use of energy in buildings will contribute to savings and cost reductions, save finite resources, and take a step towards a low carbon environment. Given the critical role played by energy management in buildings, the study identified five (05) subcategories under the energy management system which are essential for SBs. These are intelligent control and management, energy-efficient procedures development and usage, adaptive energy systems, energy storage, smart metering, and peak demand calculation.

\subsubsection{Health and Safety}

The World Health Organization (WHO) has defined the smartness of modern buildings according to the health and safety perspective as a combination of safe and green features. SBs must strengthen use of architectural and technology solutions that lead to the enhancement or preservation of users' health, thereby improving their physical and mental well-being [5]. The criteria support the risk management necessity of smart buildings by incorporating actions that are required to minimize losses caused by casual events [55]. Internet of Medical Things (IoMT) sector predictions expresses that the IoT market will reach 3.7 million connected medical devices worldwide by 2021 [33]. Further researchers state that this allows all the individual occupants of the building to contact medical ser- 
vice providers in any situation where health care assistance is needed to track the precise locations of medical assets and patients in order to enhance the efficiency of treatments. Hence, health and safety play a vital role in SBs. The criteria include assistance to people for health care, security and access control, emergency response, movement detection, and weather prediction and disaster response are among the identified criteria.

\subsubsection{Building Automation}

Building automation systems (BAS) have evolved over the past 10-20 years to allow greater control of energy use within a building in the form of building energy management systems (BEMSs) [40]. According to the author, BAS controls and monitors interconnected systems such as mechanical, electrical, plumbing systems, and control devices (i.e., sensors, utility meters, variable speed drivers, actuators, and dampers) using underlying control networks. They enable monitoring and managing of building environments depending on the user-defined conditions [23]. SBs and their integration with the smart grid resulted due to the emergence of technology and protocols [40]. These enable effective and smooth communication of BAS with equipment and systems in the building. Under this category, the study identified five (05) subcriteria that are essential in determining the level of smartness, i.e., occupants' traffic control, building management system with intelligent controls, data gathering devices with sensor networks, and remote monitoring assets tracking.

\subsubsection{Occupancy Comfort}

SBs should utilize architectural and technology solutions and contribute to environmental comfort, to enhance the quality of life and welfare of users while ensuring environmental sustainability [5]. According to Daissaoui et al. [56], the fundamental requirement of buildings is to maintain comfortable living circumstances for building occupants, hence occupant comfort is another significant concern of SBs. Furthermore, because individuals spend an average of $80 \%$ of their lives indoors, a healthier and more comfortable indoor environment is critical for occupants' well-being and productivity [56]. Morvaj et al. [23] defined smart appliances for personalized control, which can be a part of building automation to monitor building conditions depending on the user's defined conditions. According to Dounis and Caraiscos [57], three fundamental factors that determine a building environment's quality are thermal comfort, visual comfort, and air quality. However, the study identified six criteria that determine the comfort levels of a SB. These criteria, as summarized in Table 1 are indoor air quality, visual comfort, acoustic comfort, thermal comfort, smart appliances for personalized control, and space utilization and passive design.

\subsubsection{Communication and Data Sharing}

SBs need data processing and sharing from multiple and diverse sources and require multiple and diverse processors (human or hardware) to achieve a synergistic effect, i.e., an effect greater than the sum of their individual effects [45]. With the growth of the Internet of Things, collected data are being encrypted and stored in the cloud to prevent data loss and data misuse by external parties. According to Molnar and Mohamed [58], data-based approaches in the fault detection and diagnosis area have been used in many different buildings. The set of fundamental technologies based on IoT that enables the control and data creation for various services is the heartbeat of intelligent buildings [56]. Moreover, SBs require equipment, infrastructure, and systems for managing telecommunications services [5]. Hence, communication and data sharing play a vital role in SBs. Under communication and data sharing, the key subcriteria identified are cloud-based data sharing and storage, data protection, digital infrastructure, wireless technologies, and cyber-physical systems. 


\subsubsection{Sustainability}

Designing ideal facilities requires guaranteeing the health of buildings, ensuring they are renovated and updated throughout their life and, at the same time, meeting sustainability goals [49]. The systematic design and construction of a SB is a must to achieve the environmental compromises and sustainability objectives. A growing challenge for the 21st-century-built environment is matching the intermittent renewable electrical energy supply with various demanding factors such as (a) population growth (b) concerns about carbon emissions, and (c) energy produced by solar photovoltaics and wind energy [40]. Hence, SBs need to be well equipped to meet renewable energy challenges. With these concerns, five (05) sub-criteria contributing to the sustainability of SBs were identified, namely, renewable energy source, material conservation, water conservation, land conservation, and usage of waste management strategies.

Based on the above elaboration and the review results presented in Table 1, Figure 1 was developed to provide an overall picture of the SB evaluation criteria. These results are to be used in developing the scoring system to evaluate the smartness level of commercial buildings.
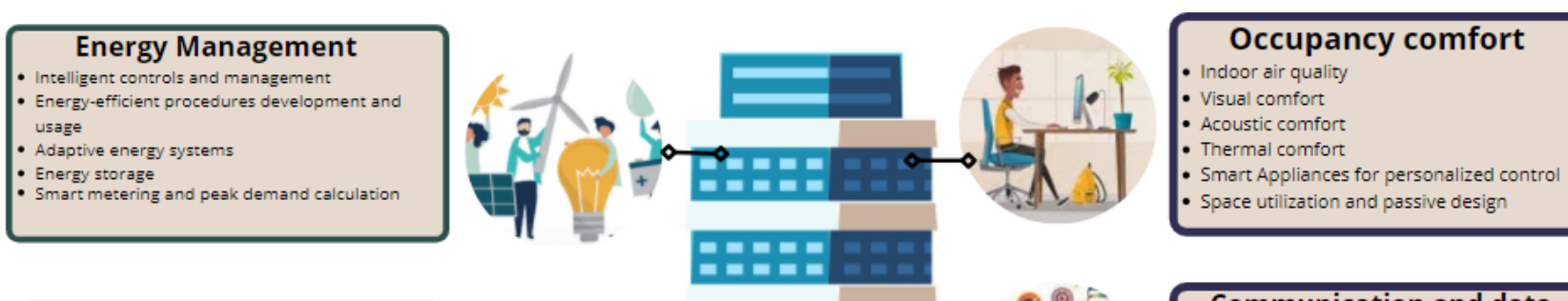

\section{Health and Safety}

- Assistance to people for health care

- Security and access control

- Emergency response

- Movement detection

Weather prediction and disaster response

\section{Building Automation}

\section{- Automatic occupants' traffic control}

- Building management system with intelligent

controls

- Asset tracking

- Data gathering devices with sensor networks

- Remote monitoring

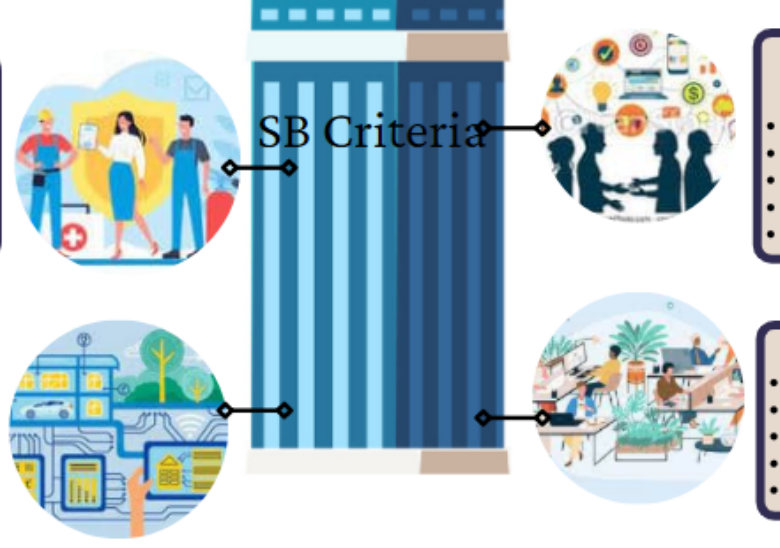

Communication and data sharing

- Cloud-based data sharing and storage

- Data protection

- Internet of Things

Wireless technologies

Cyber-physical system

Sustainability features

- Renewable energy source

- Material Conservation

Water Conservation

- Land Conservation

Usage of waste management strategies

Figure 1. Summary of literature review findings: criteria to evaluate SBs.

\section{Material and Methods}

This study aims to develop a scoring system to assess the smartness level of commercial buildings. To peruse the research aim, both primary and secondary data were utilized by the study. The research process is presented in Figure 2.

\subsection{Research Design}

To generate primary data, the mixed methods approach (MMA), including quantitative and qualitative questions, was utilized in this study. As stated by Herrera [59], MMA is an alternative to expanding the analytical power of media as a mix of quantitative and qualitative makeup. Quantitative and qualitative data can be mixed in three different ways, namely: (a) by connecting (having one data type build on the other), (b) by merging (to compare or relate results from both data types), or (c) by embedding (to explain one data type results by the other) [59]. Therefore, this is a concurrent embedded mixedmethods study, with qualitative insights being explored to complement the findings from the quantitative survey. 


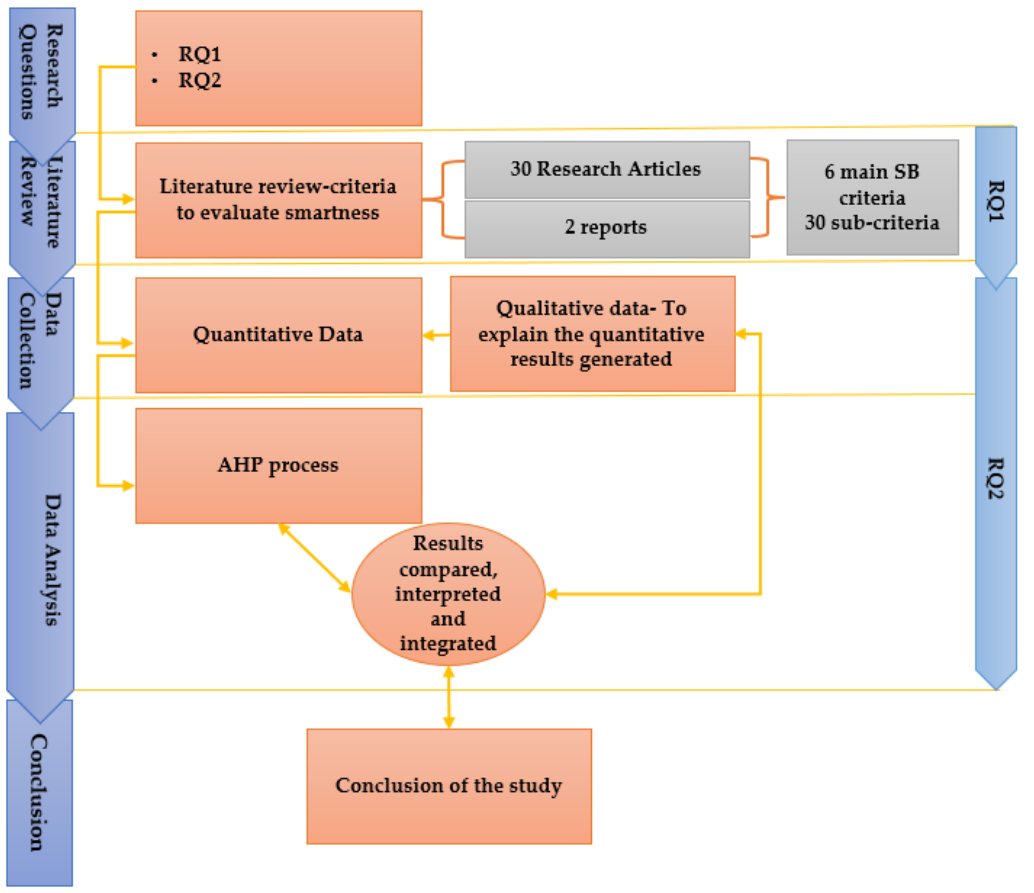

Figure 2. Research process.

\subsection{Literature Review}

A literature review was carried out to determine the criteria to evaluate the smartness of commercial buildings. According to literature findings, criteria for smart buildings are categorized into six main categories. These are energy management, occupants' health and safety, automation, occupancy comfort, communication and data sharing, and sustainability.

\subsection{Data Collection and Dissemination}

Following the systematic literature review, preliminary interviews were carried out among five (05) experts. The experts validated the criteria to evaluate the level of smartness of commercial buildings identified through literature review, and accordingly, the questionnaire was refined. Subsequently, semi-structured interviews were carried out to identify the relative importance of the evaluating criteria and to explore the reasoning leading to individual choices. The developed questionnaire is composed of two segments; the relative importance of key criteria with reasoning and the relative importance of sub-criteria for each criterion. An extract of the questionnaire (Table 2) is as follows.

Convenience sampling is a type of nonprobability or nonrandom sampling where members of the target population that meet certain practical criteria, such as easy accessibility, geographical proximity, availability at a given time, or the willingness to participate, are included for the study [60]. Therefore, under convenience sampling, 35 experts on smart commercial buildings were selected for empirical investigation based on their experience in (a) planning, (b) designing, (c) constructing, and (d) operating smart commercial buildings. Instead of selecting experts randomly from the defined categories, the experts with more than ten years of experience in the field that were readily available to participate were selected. These experts were interviewed through an online platform for a period of $40 \mathrm{~min}$ to $1 \mathrm{~h}$.

According to the Oxford business group [61], the Sri Lankan government's LKR 40 billion Western Region Megapolis Planning Project (WRMPP) will certainly spur commercial real estate in the western region of Sri Lanka. According to the WRMPP Master Plan, the western region produced $40 \%$ of Sri Lanka's total GDP and is home to 5.8 million people, or $29 \%$ of the country's population. Hence, commercial buildings in the western 
region of the country, which include office complexes, retail shopping malls, and mixed development projects, were considered in the study. The composition of the experts interviews is shown in Figure 3.

Table 2. An extract of the AHP questionnaire for pairwise comparison.

\begin{tabular}{|c|c|c|c|c|c|c|c|c|c|c|}
\hline 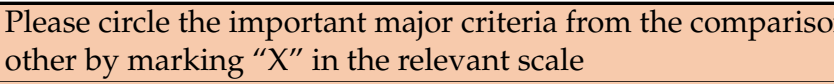 & & & & & & & & & & Special \\
\hline Comparison Pair (A-automation, B-communication & & & & $\mathrm{elc}$ & $\operatorname{Im} 1$ & orta & & & & Com- \\
\hline $\begin{array}{l}\text { and data sharing, C-occupants' comfort, D-energy } \\
\text { management, E-health and safety, F-sustainability) }\end{array}$ & 1 & 2 & 3 & 4 & 5 & 6 & 7 & 8 & 9 & \\
\hline A vs. B & & & & & & & & & & \\
\hline A vs. C & & & & & & & & & & \\
\hline A vs. D & & & & & & & & & & \\
\hline A vs. E & & & & & & & & & & \\
\hline A vs. F & & & & & & & & & & \\
\hline B vs. C & & & & & & & & & & \\
\hline B vs. D & & & & & & & & & & \\
\hline B vs. E & & & & & & & & & & \\
\hline B vs. F & & & & & & & & & & \\
\hline C vs. D & & & & & & & & & & \\
\hline C vs. E & & & & & & & & & & \\
\hline C vs. F & & & & & & & & & & \\
\hline D vs. E & & & & & & & & & & \\
\hline D vs. F & & & & & & & & & & \\
\hline E vs. F & & & & & & & & & & \\
\hline $\begin{array}{l}\text { Please circle the important sub-criteria from the comparison } \\
\text { other by marking " } X \text { " in the relevant scale }\end{array}$ & por & & $f+$ & & & & & th & & Special \\
\hline Comparison Pair (A1-BMS, A2-automatic occupants & & & & el c & $\operatorname{Im}$ & orta & & & & Com- \\
\hline $\begin{array}{l}\text { traffic control, A3-asset tracking, A4-remote monitoring, } \\
\text { A5-data gathering devices with sensor networks) }\end{array}$ & 1 & 2 & 3 & 4 & 5 & 6 & 7 & 8 & 9 & \\
\hline A1 vs. A2 & & & & & & & & & & \\
\hline A1 vs. A3 & & & & & & & & & & \\
\hline A1 vs. A4 & & & & & & & & & & \\
\hline A1 vs. A5 & & & & & & & & & & \\
\hline A2 vs. A3 & & & & & & & & & & \\
\hline A2 vs. A4 & & & & & & & & & & \\
\hline A2 vs. A5 & & & & & & & & & & \\
\hline A3 vs. A4 & & & & & & & & & & \\
\hline A3 vs. A5 & & & & & & & & & & \\
\hline A4 vs. A5 & & & & & & & & & & \\
\hline
\end{tabular}

\subsection{Data Analysis}

In choosing the best evaluation or decision-making method for criteria determination, studies and the scientific literature in this field suggest that the problem could be solved by applying the multi-criteria decision-making method [62]. Further, AHP is a multi-criteria approach that facilitates decision making with conflict criteria and alternatives. Therefore, data analysis was carried out based on AHP in order to determine the criteria and understand the relative importance of each criterion in determining the level of smartness of commercial buildings, which would finally lead to developing the scoring system. To support this, the interview guideline was designed based on the standard AHP questionnaire format originally proposed by Saaty [63]. Further, the ratio scale presented by Saaty [63] was utilized by the study in developing the questionnaire. According to Wong and Li [64], the steps of AHP include (a) defining the problem and objective, (b) development of the hierarchy, (c) pairwise comparison, and (d) normalizing and consistency calculation. 

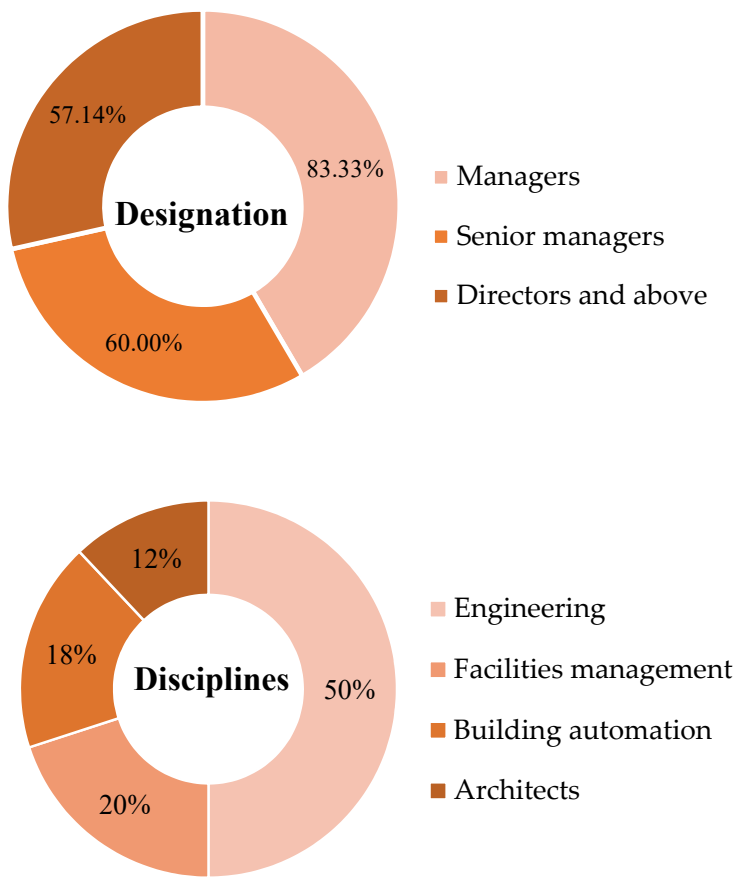

Figure 3. Demographic profile of experts.

\subsubsection{Development of the Hierarchy}

Concerning the steps mentioned by Saaty [63] in implementing the AHP tool, the study first decomposed the research into a hierarchy of goal, criteria, sub-criteria, and alternatives. The developed hierarchy is presented in Figure 4. The hierarchy was developed based on literature review findings in Table 1.

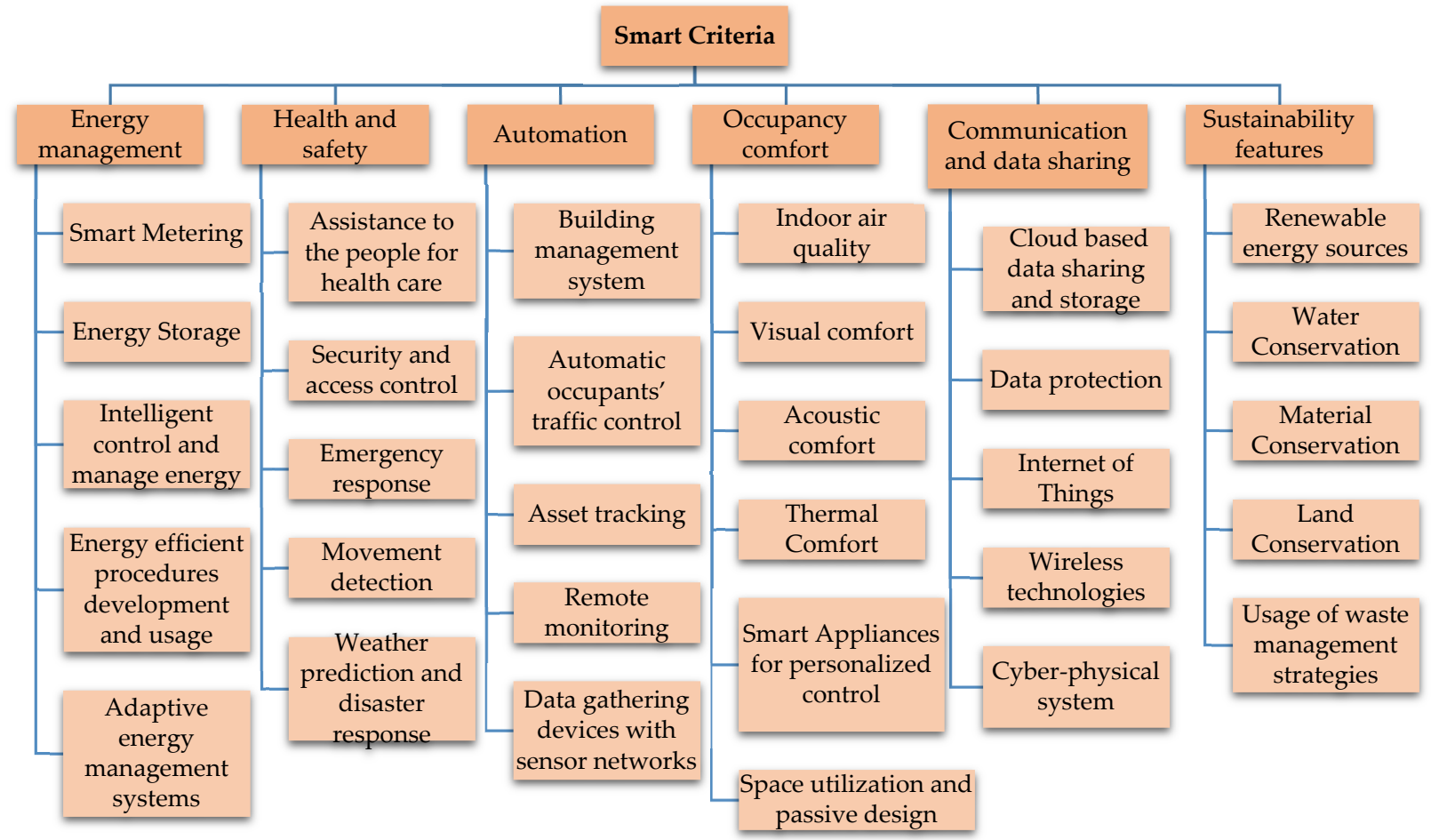

Figure 4. AHP hierarchy of smart building criteria. 


\subsubsection{Pairwise Comparison}

Secondly, the gathered data from the questionnaire survey was entered into the pairwise comparison matrices based on Saaty's [63] eigenvector model. A sample of the pairwise comparison matrix is illustrated in Table 3. The respondents were directed to compare each main criteria as pairs to indicate the relative importance. Averages of the responses and their reciprocals were recorded in the matrices as $\mathrm{K}_{1}, \mathrm{~K}_{2}, \mathrm{~K}_{3}, \mathrm{~K}_{4}, \mathrm{~K}_{5}, \mathrm{~K}_{6}$, $\mathrm{K}_{7}, \mathrm{~K}_{8}, \mathrm{~K}_{9}, \mathrm{~K}_{10}, \mathrm{~K}_{11}, \mathrm{~K}_{12}, \mathrm{~K}_{13}, \mathrm{~K}_{14}$, and $\mathrm{K}_{15}$ and the sum of each column was calculated afterward and is indicated as $\mathrm{L}_{1}, \mathrm{~L}_{2}, \mathrm{~L}_{3}, \mathrm{~L}_{4}$, and $\mathrm{L}_{5}$.

Table 3. Pairwise comparison of SB criteria.

\begin{tabular}{ccccccc}
\hline $\begin{array}{c}\text { Smartness } \\
\text { Criteria }\end{array}$ & $\mathbf{A}$ & $\mathbf{B}$ & $\mathbf{C}$ & $\mathbf{D}$ & $\mathbf{E}$ & $\mathbf{F}$ \\
\hline $\mathrm{A}$ & 1 & $\mathrm{~K}_{1}$ & $\mathrm{~K}_{2}$ & $\mathrm{~K}_{3}$ & $\mathrm{~K}_{4}$ & $\mathrm{~K}_{5}$ \\
\hline $\mathrm{B}$ & $1 / \mathrm{K}_{1}$ & 1 & $\mathrm{~K}_{6}$ & $\mathrm{~K}_{7}$ & $\mathrm{~K}_{8}$ & $\mathrm{~K}_{9}$ \\
\hline $\mathrm{C}$ & $1 / \mathrm{K}_{2}$ & $1 / \mathrm{K}_{6}$ & 1 & $\mathrm{~K}_{10}$ & $\mathrm{~K}_{11}$ & $\mathrm{~K}_{12}$ \\
\hline $\mathrm{D}$ & $1 / \mathrm{K}_{3}$ & $1 / \mathrm{K}_{7}$ & $1 / \mathrm{K}_{10}$ & 1 & $\mathrm{~K}_{13}$ & $\mathrm{~K}_{14}$ \\
\hline $\mathrm{E}$ & $1 / \mathrm{K}_{4}$ & $1 / \mathrm{K}_{8}$ & $1 / \mathrm{K}_{11}$ & $1 / \mathrm{K}_{13}$ & 1 & $\mathrm{~K}_{15}$ \\
\hline $\mathrm{F}$ & $1 / \mathrm{K}_{5}$ & $1 / \mathrm{K}_{9}$ & $1 / \mathrm{K}_{12}$ & $1 / \mathrm{K}_{14}$ & $1 / \mathrm{K}_{15}$ & 1 \\
\hline Total & $\mathrm{L}_{1}$ & $\mathrm{~L}_{2}$ & $\mathrm{~L}_{3}$ & $\mathrm{~L}_{4}$ & $\mathrm{~L}_{5}$ & $\mathrm{~L}_{6}$ \\
\hline
\end{tabular}

\subsubsection{Normalizing}

Following the pairwise comparison, normalization was done by dividing each component from the sum of each column in the comparison table. Table 4 illustrates a model of the normalization matrix. Normalizing the entries is done by dividing the entry by the sum of each column in pairwise comparison matrices. Performance score (PS) is generated by dividing the row sum from the total sum. M1, M2, M3, X4, and M5 indicate the sum of each row after normalizing. $M$ is the sum of the sum column.

Table 4. Normalization data entries of pairwise comparison of SB criteria.

\begin{tabular}{ccccccccc}
\hline $\begin{array}{c}\text { Smartness } \\
\text { Criteria }\end{array}$ & $\mathbf{A}$ & $\mathbf{B}$ & $\mathbf{C}$ & $\mathbf{D}$ & $\mathbf{E}$ & $\mathbf{F}$ & Sum & Performance Score \\
\hline $\mathrm{A}$ & $1 / \mathrm{L}_{1}$ & $\mathrm{~K}_{1} / \mathrm{L}_{2}$ & $\mathrm{~K}_{2} / \mathrm{L}_{3}$ & $\mathrm{~K}_{3} / \mathrm{L}_{4}$ & $\mathrm{~K}_{4} / \mathrm{L}_{5}$ & $\mathrm{~K}_{5} / \mathrm{L}_{6}$ & $\mathrm{M}_{1}$ & $\mathrm{M} 1 / \mathrm{M}=\mathrm{N} 1$ \\
\hline $\mathrm{B}$ & $\left(1 / \mathrm{K}_{1}\right) / \mathrm{L}_{1}$ & $1 / \mathrm{L}_{2}$ & $\mathrm{~K}_{6} / \mathrm{L}_{3}$ & $\mathrm{~K}_{7} / \mathrm{L}_{4}$ & $\mathrm{~K}_{8} / \mathrm{L}_{5}$ & $\mathrm{~K}_{9} / \mathrm{L}_{6}$ & $\mathrm{M}_{2}$ & $\mathrm{M} 2 / \mathrm{M}=\mathrm{N} 2$ \\
\hline $\mathrm{C}$ & $\left(1 / \mathrm{K}_{2}\right) / \mathrm{L}_{1}$ & $\left(1 / \mathrm{K}_{6}\right) / \mathrm{L}_{2}$ & $1 / \mathrm{L}_{3}$ & $\mathrm{~K}_{10} / \mathrm{L}_{4}$ & $\mathrm{~K}_{11} / \mathrm{L}_{5}$ & $\mathrm{~K}_{12} / \mathrm{L}_{6}$ & $\mathrm{M}_{3}$ & $\mathrm{M} 3 / \mathrm{M}=\mathrm{N} 3$ \\
\hline $\mathrm{D}$ & $\left(1 / \mathrm{K}_{3}\right) / \mathrm{L}_{1}$ & $\left(1 / \mathrm{K}_{7}\right) / \mathrm{L}_{2}$ & $\left(1 / \mathrm{K}_{10}\right) / \mathrm{L}_{3}$ & $1 / \mathrm{L}_{4}$ & $\mathrm{~K}_{13} / \mathrm{L}_{5}$ & $\mathrm{~K}_{14} / \mathrm{L}_{6}$ & $\mathrm{M}_{4}$ & $\mathrm{M} 4 / \mathrm{M}=\mathrm{N} 4$ \\
\hline $\mathrm{E}$ & $\left(1 / \mathrm{K}_{4}\right) / \mathrm{L}_{1}$ & $\left(1 / \mathrm{K}_{8}\right) / \mathrm{L}_{2}$ & $\left(1 / \mathrm{K}_{11}\right) / \mathrm{L}_{3}$ & $\left(1 / \mathrm{K}_{13}\right) / \mathrm{L}_{4}$ & $1 / \mathrm{L}_{5}$ & $\mathrm{~K}_{15} / \mathrm{L}_{6}$ & $\mathrm{M}_{5}$ & $\mathrm{M} 5 / \mathrm{M}=\mathrm{N} 5$ \\
\hline $\mathrm{F}$ & $\left(1 / \mathrm{K}_{5}\right) / \mathrm{L}_{1}$ & $\left(1 / \mathrm{K}_{9}\right) / \mathrm{L}_{2}$ & $\left(1 / \mathrm{K}_{12}\right) / \mathrm{L}_{3}$ & $\left(1 / \mathrm{K}_{14}\right) / \mathrm{L}_{4}$ & $\left(1 / \mathrm{K}_{15}\right) / \mathrm{L}_{5}$ & $1 / \mathrm{L}_{6}$ & $\mathrm{M}_{6}$ & $\mathrm{M} 6 / \mathrm{M}=\mathrm{N} 6$ \\
\hline
\end{tabular}

\subsubsection{Consistency Calculation}

Finally, the consistency index was computed to test the accuracy and validate the findings using the below formula.

The consistency index (CI) is a test of accuracy. The consistency ratio (CR) is derived using the randomized index (RI) and the average CI for randomly filled matrices. The steps leading to the consistency ratio are as follows:

$$
\mathrm{CR}=\frac{\mathrm{CI}}{\mathrm{RI}}
$$

Step 1: Entries in the pairwise comparison matrix are multiplied by the performance score to obtain the eigenvector. $P$ is a new vector obtained through the addition of each row. Table 5 illustrates the model calculation table for consistency calculations. 
Table 5. Model consistency calculation matrix.

\begin{tabular}{|c|c|c|c|c|c|c|c|c|}
\hline $\begin{array}{c}\text { Smartness } \\
\text { Criteria }\end{array}$ & A & B & $\mathrm{C}$ & D & E & $\mathbf{F}$ & $\begin{array}{c}\text { Sum } \\
\text { Value }\end{array}$ & Sum/Weight \\
\hline $\mathbf{A}$ & $1 \times \mathrm{N} 1$ & $\mathrm{~K}_{1} \times \mathrm{N} 2$ & $\mathrm{~K}_{2} \times \mathrm{N} 3$ & $\mathrm{~K}_{3} \times \mathrm{N} 4$ & $\mathrm{~K}_{4} \times \mathrm{N} 5$ & $\mathrm{~K}_{5} \times \mathrm{N} 6$ & P1 & $\mathrm{P} 1 / \mathrm{N} 1$ = a1 \\
\hline B & $1 / \mathrm{K}_{1} \times \mathrm{N} 1$ & $1 \times \mathrm{N} 2$ & $\mathrm{~K}_{6} \times \mathrm{N} 3$ & $\mathrm{~K}_{7} \times \mathrm{N} 4$ & $\mathrm{~K}_{8} \times \mathrm{N} 5$ & $\mathrm{~K}_{9} \times \mathrm{N} 6$ & P2 & $\mathrm{P} 2 / \mathrm{N} 2=\mathrm{a} 2$ \\
\hline $\mathrm{C}$ & $1 / \mathrm{K}_{2} \times \mathrm{N} 1$ & $1 / \mathrm{K}_{6} \times \mathrm{N} 2$ & $1 \times \mathrm{N} 3$ & $\mathrm{~K}_{10} \times \mathrm{N} 4$ & $\mathrm{~K}_{11} \times \mathrm{N} 5$ & $\mathrm{~K}_{12} \times \mathrm{N} 6$ & P3 & $\mathrm{P} 3 / \mathrm{N} 3=\mathrm{a} 3$ \\
\hline D & $1 / \mathrm{K}_{3} \times \mathrm{N} 1$ & $1 / \mathrm{K}_{7} \times \mathrm{N} 2$ & $1 / \mathrm{K}_{10} \times \mathrm{N} 3$ & $1 \times \mathrm{N} 4$ & $\mathrm{~K}_{13} \times \mathrm{N} 5$ & $\mathrm{~K}_{14} \times \mathrm{N} 6$ & $\mathrm{P} 4$ & $\mathrm{P} 4 / \mathrm{N} 4=\mathrm{a} 4$ \\
\hline $\mathbf{E}$ & $1 / \mathrm{K}_{4} \times \mathrm{N} 1$ & $1 / \mathrm{K}_{8} \times \mathrm{N} 2$ & $1 / \mathrm{K}_{11} \times \mathrm{N} 3$ & $1 / \mathrm{K}_{13} \times \mathrm{N} 4$ & $1 \times \mathrm{N} 5$ & $\mathrm{~K}_{15} \times \mathrm{N} 6$ & P5 & $\mathrm{P} 5 / \mathrm{N} 5=\mathrm{a} 5$ \\
\hline $\mathbf{F}$ & $1 / \mathrm{K}_{5} \times \mathrm{N} 1$ & $1 / \mathrm{K}_{9} \times \mathrm{N} 2$ & $1 / \mathrm{K}_{12} \times \mathrm{N} 3$ & $1 / \mathrm{K}_{14} \times \mathrm{N} 4$ & $1 / \mathrm{K}_{15} \times \mathrm{N} 5$ & $1 \times \mathrm{N} 6$ & Z5 & $\mathrm{Z} 5 / \mathrm{N} 5=\mathrm{a} 5$ \\
\hline
\end{tabular}

Step 2: $\lambda_{\max }$ is the average value of the column sum.

$$
\lambda_{\max }=\frac{(a 1+a 2+a 3+a 4+a 5+\ldots a n)}{n}
$$

Step 3: Consistency index (CI) is calculated as per the following equation.

$$
\mathrm{CI}=\frac{\lambda \max -n}{n-1}
$$

Hence, the consistency ratio can be derived from the following equation. RI was obtained using Table 6.

$$
\mathrm{CR}=\frac{\mathrm{CI}}{\mathrm{RI}}
$$

Table 6. Saaty's random consistency index.

\begin{tabular}{ccccccccccc}
\hline $\mathrm{N}$ & 1 & 2 & 3 & 4 & 5 & 6 & 7 & 8 & 9 & 10 \\
\hline $\mathrm{RI}$ & 0.00 & 0.00 & 0.52 & 0.89 & 1.11 & 1.25 & 1.35 & 1.40 & 1.45 & 1.49 \\
\hline
\end{tabular}

Deng [65] points out that Saaty's thumb principle only agrees when $C R<0.1$. The CR of the study result agreed with Saaty's thumb principle.

\section{Results}

\subsection{A Scoring System to Evaluate the Level of Smartness of Commercial Buildings}

Determining the smart criterion of commercial buildings was considered to be a key requirement in order to derive a robust scoring system from evaluating the smartness level of commercial buildings. Table 7 presents the scoring systems along with the criterion and sub-criterion developed to evaluate the smartness of commercial buildings. The scheme gains scores based on key criteria and sub-criterion necessary for a SB. The total of the sub-criteria will be multiplied by the main score of the relevant key criterion. The total score of the selected building will then be the sum of all six major intelligent evaluation criteria.

Table 7. Scoring system to evaluate smart commercial buildings.

\begin{tabular}{ccc}
\hline Criterion Rank & Smart Criteria & Performance Score (\%) \\
\hline$(1)$ & Building automation & $45.59(\mathrm{~A})$ \\
\hline 1 & Building management system (BMS) & $22.43(\mathrm{~A} 1)$ \\
\hline 2 & Automatic occupants' traffic control & $21.46(\mathrm{~A} 2)$ \\
\hline 3 & Asset tracking & $19.84(\mathrm{~A} 3)$ \\
\hline 4 & Remote monitoring & $19.27(\mathrm{~A} 4)$ \\
\hline 5 & Data gathering devices with sensor & $16.99(\mathrm{~A} 5)$ \\
\hline
\end{tabular}


Table 7. Cont.

\begin{tabular}{|c|c|c|}
\hline Criterion Rank & Smart Criteria & Performance Score $(\%)$ \\
\hline \multicolumn{3}{|c|}{ Total Score $=(\mathrm{A} 1+\mathrm{A} 2+\mathrm{A} 3+\mathrm{A} 4+\mathrm{A} 5) \times \mathrm{A}$} \\
\hline$(2)$ & Communication and data sharing & $18.76(\mathrm{~B})$ \\
\hline 1 & Cloud-based data sharing and storage & $28.96(\mathrm{~B} 1)$ \\
\hline 2 & Data protection & 24.25 (B2) \\
\hline 3 & Internet of Things & 20.52 (B3) \\
\hline 4 & Wireless technologies & 15.27 (B4) \\
\hline 5 & Cyberphysical system & $11.00(\mathrm{~B} 5)$ \\
\hline \multicolumn{3}{|c|}{ Total Score $=(\mathrm{B} 1+\mathrm{B} 2+\mathrm{B} 3+\mathrm{B} 4+\mathrm{B} 5) \times \mathrm{B}$} \\
\hline (3) & Occupants' comfort & $12.91(\mathrm{C})$ \\
\hline 1 & Indoor air quality & $24.21(\mathrm{C} 1)$ \\
\hline 2 & Visual comfort & $21.09(\mathrm{C} 2)$ \\
\hline 3 & Acoustic comfort & $18.32(\mathrm{C} 3)$ \\
\hline 4 & Thermal comfort & $14.71(\mathrm{C} 4)$ \\
\hline 5 & Smart appliances for personalized control & $13.11(\mathrm{C} 5)$ \\
\hline 6 & Space utilization and passive design & $8.56(\mathrm{C} 6)$ \\
\hline \multicolumn{3}{|c|}{ Total Score $=(\mathrm{C} 1+\mathrm{C} 2+\mathrm{C} 3+\mathrm{C} 4+\mathrm{C} 5+\mathrm{C} 6) \times \mathrm{C}$} \\
\hline$(4)$ & Energy management & 8.94 (D) \\
\hline 1 & Smart metering & $33.82(\mathrm{D} 1)$ \\
\hline 2 & Energy storage & $24.46(\mathrm{D} 2)$ \\
\hline 3 & $\begin{array}{l}\text { Intelligent controls for energy } \\
\text { management }\end{array}$ & 17.27 (D3) \\
\hline 4 & $\begin{array}{l}\text { Energy efficient procedures development } \\
\text { and usage }\end{array}$ & 14.04 (D4) \\
\hline 5 & Adaptive energy management systems & 10.42 (D5) \\
\hline \multicolumn{3}{|c|}{ Total Score $=(\mathrm{D} 1+\mathrm{D} 2+\mathrm{D} 3+\mathrm{D} 4+\mathrm{D} 5) \times \mathrm{D}$} \\
\hline$(5)$ & Occupants' health and safety & $8.51(\mathrm{E})$ \\
\hline 1 & Assistance to people for health care & $29.86(\mathrm{E} 2)$ \\
\hline 2 & Security and access control & $24.63(\mathrm{E} 1)$ \\
\hline 3 & Emergency response & $17.17(\mathrm{E} 3)$ \\
\hline 4 & Movement detection & $14.71(\mathrm{E} 5)$ \\
\hline 5 & Weather prediction and disaster response & $13.64(\mathrm{E} 4)$ \\
\hline \multicolumn{3}{|c|}{ Total Score $=(\mathrm{E} 1+\mathrm{E} 2+\mathrm{E} 3+\mathrm{E} 4+\mathrm{E} 5) \times \mathrm{E}$} \\
\hline (6) & Sustainability features & $5.28(\mathrm{~F})$ \\
\hline 1 & Renewable energy sources & $32.57(\mathrm{~F} 1)$ \\
\hline 2 & Water conservation & $25.71(\mathrm{~F} 2)$ \\
\hline 3 & Material conservation & $16.50(\mathrm{~F} 3)$ \\
\hline 4 & Land conservation & $13.25(\mathrm{~F} 4)$ \\
\hline 5 & Usage of waste management strategies & $11.98(\mathrm{~F} 5)$ \\
\hline \multicolumn{3}{|c|}{ Total Score $=(\mathrm{F} 1+\mathrm{F} 2+\mathrm{F} 3+\mathrm{F} 4+\mathrm{F} 5) \times \mathrm{F}$} \\
\hline & Final Score $=\mathrm{A}+\mathrm{B}+\mathrm{C}+\mathrm{D}+\mathrm{E}+\mathrm{F}$ & \\
\hline
\end{tabular}

The contribution made by major criteria in assessing the overall smartness of a building can be summarized and presented in Figure 5. This figure provides a summary version of Table 7 to depict the criteria that significantly contribute to the scoring system. 


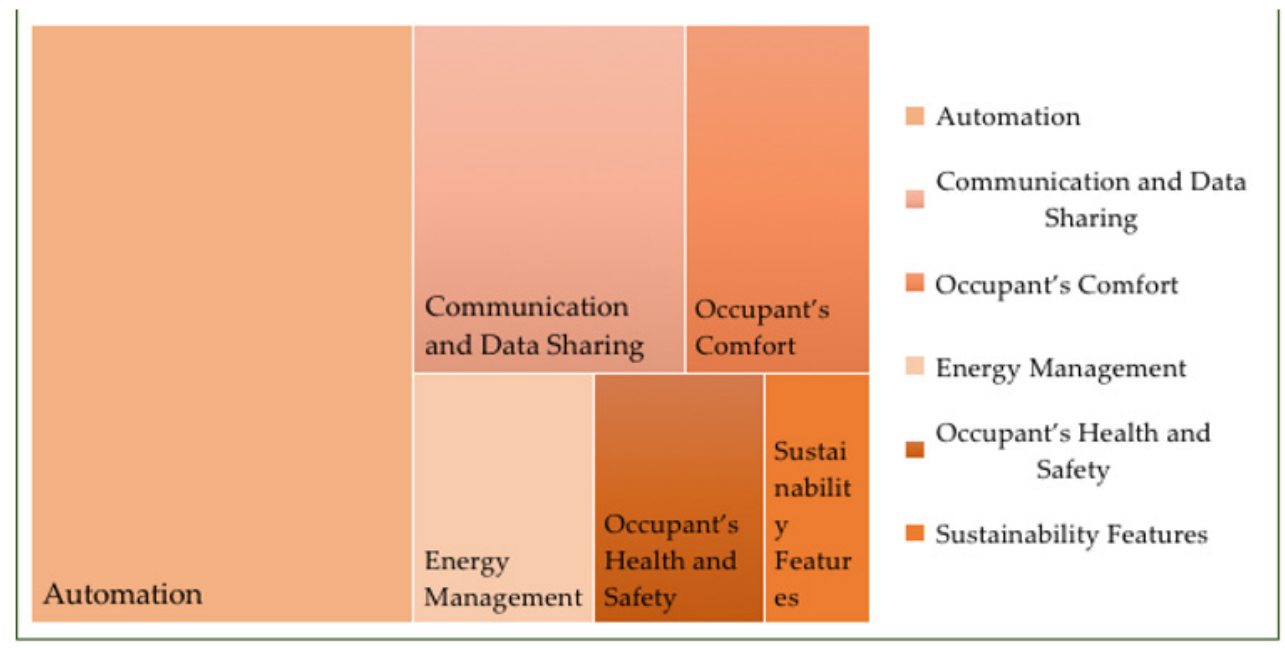

Figure 5. Major criteria for evaluating smart buildings.

According to Figure 5, the most influential criteria in determining smartness is automation followed by communication and data sharing, occupants' comfort, energy management, occupants' health and safety, and sustainability features. The composition of sub-criteria under respective major criteria is illustrated in Figure 6.

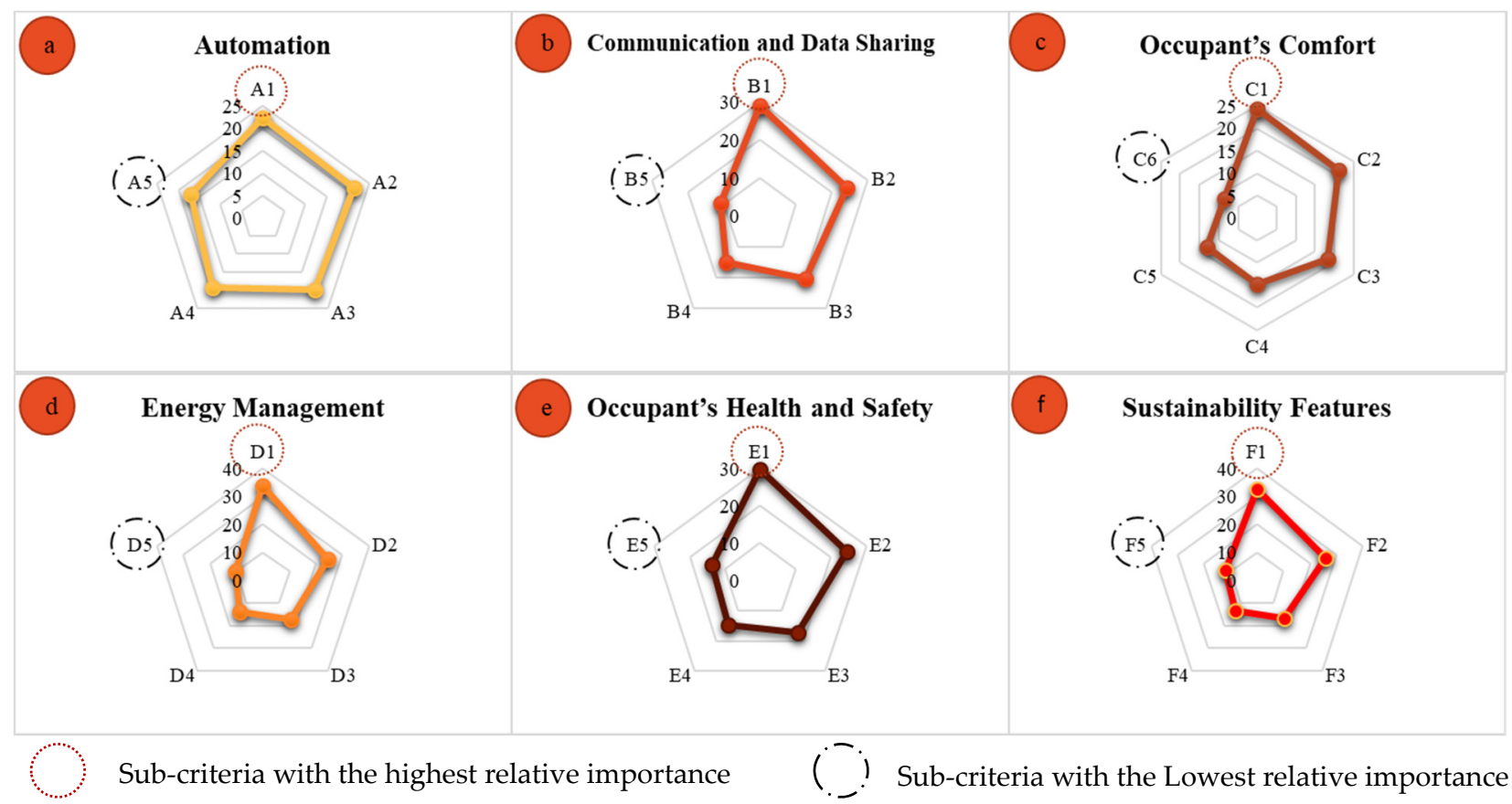

Figure 6. Composition of subcriteria related to smart building: (a) subcriteria related to automation; (b) subcriteria related to communication and data sharing; (c) subcriteria related to occupants' comfort; (d) subcriteria related to energy management; (e) subcriteria related to occupants' health and safety; and (f) subcriteria related to sustainability features.

Figure 6 provides a more detailed representation of Table 7 in terms of the individual criteria and the respective sub-criteria. These criteria and sub-criteria are subjected to discussion in the following sections.

\subsubsection{Building Automation}

The findings of the study revealed building automation as the most significant criterion $(45.59 \%)$ that determines the level of building smartness. Similarly, Kastner et al. [66] revealed that automation is the most significant criterion as it pedals the mechanical, 
electronic, and lighting systems while ensuring the operation performance of the building as well as the comfort and safety of the occupants.

Within the segment, as depicted in Figure 6a, BMS with intelligent controls achieved the highest weight $(22.43 \%)$. Automation engineers in the industry manifested that there is a considerable increment in the usage of BMS in Sri Lanka over the past few decades, with building owners recognizing its importance. Examples of quotes include:

"We have been experiencing rapid growth in the usage of BMS systems. Mostly these are requested by the clients/developers to attract more clients by increasing comfort level, energy efficiency in their buildings" (Automation engineer).

"Presently clients/developers are more likely to obtain certifications to their organizations for this BMS can be used as a marketing tool" (Facilities manager).

As presented in Figure 6a, automatic occupant traffic control is the second most significant criterion with a relative weight of $21.46 \%$ since it involves several imperative situations such as emergencies and morning and evening peak times in commercial buildings. In light of this, several comments were made by the respondents where they discussed the nature of traffic in elevators, escalators, staircases, and corridors at peak hours. A facilities manager added that

"A proper vertical transportation system is essential, especially in high-rise office buildings. During rush hours, we have experienced people being jammed packed in elevators and escalators due to poor handling of these systems manually by lift operators. In an emergency, the situation could be worse. So properly automated transportation system has a vital role when it comes to health and safety aspects and efficiency of the building performances".

Emphasis was made by the respondents on the requirement of an automatic occupants' traffic control system to direct people appropriately to relevant destinations while ensuring efficiency and limiting delays.

According to Figure 6a, asset tracking gained a relative weight of $19.84 \%$ within the criteria to evaluate the smartness of commercial buildings and was ranked third. The criterion was commented for its popularity and emergence among clients as a crucial aspect of ensuring the reliability and longevity of assets. As an example, a respondent stated that

"Asset tracking is a key function requested by clients in new projects in order to maintain the reliability and increase the longevity of assets" (BAS engineer).

Remotely monitoring and controlling (19.27\%) a facility is a cyber-based function conducted through the internet with a handheld computer or a digital device. An automation expert stated that it had become the fourth effective criterion for a smart commercial building.

Data gathering devices with sensor networks were considered to be the fifth important criteria with a score of $16.99 \%$. Respondents manifested the nature of these devices and their key requirements within smart buildings in which the Facilities Manager commented,

"Data-gathering devices mainly deal with IoT devices involved in collecting data from energy meters, power analysers, occupancy sensors, thermostats, and water meters and so on in order to transmit data to the main control computer to report generation, further analysis and decision making" (Facilities manager).

\subsubsection{Communication and Data Sharing}

According to Table 7 and Figure $6 \mathrm{~b}$, communication and data sharing have obtained a second place as its sub-criteria emphasize the importance of digital infrastructure in order to establish better data transmitting and storing approaches in modern smart commercial buildings. According to a service engineer,

"A widespread digital network is the backbone to back the proper functioning of all other five criterions". 
As per Figure $6 \mathrm{~b}$, cloud computing (28.96\%) received the foremost place among the others due to the large data-sharing requirements of professions in the construction sector. Experts (facilities managers and engineers) manifested that the growing sophistication in technology opened up many avenues for a data breach. Hence, data protection should be given utmost importance to determine the smartness of buildings.

Within the existing criteria, IoT secured the third rank with a relative weight of $20.52 \%$ within the criteria. According to an automation engineer,

"IoT is the mainstay of digital transformation hence, contributes a greater proportion in deriving smartness".

An architect pointed out that wireless technological innovations dramatically reduce the expenditures and implementation of many hardware in an urban environment. Moreover, another expert from the engineering discipline manifested that it is one of the means of obtaining digital infrastructure. With these perspectives, the criterion received a score of $15.27 \%$; thus, appearing in the fourth place, as evident in Figure 6b. Cyber-physical systems, which form the next most significant criterion, secured the fifth rank compared with others. According to the experts, each part of the prior discussed criterion finally leads to creating cyber-physical systems.

\subsubsection{Occupants' Comfort}

According to Table 7 and Figure $6 c$, the third important criterion is occupant comfort. It was argued that SBs need to have a better environmental quality than standard buildings, and this results in a productive workplace for the occupants. After normalizing data, indoor air quality (IAQ) gained the highest score of $24.21 \%$ within the criteria. This is highlighted in Figure $6 c$. The foremost cause for emphasizing IAQ more frequently by experts are:

"Poor indoor air quality may lead to lowering the productivity of tenants" (Architect).

"Create migraine, headache, sick building syndrome and many other illnesses" (Facilities manager).

"Limiting of $\mathrm{CO}_{2}, \mathrm{CO}$ and $\mathrm{SO}_{2}$ levels in car parks and confined spaces while preventing odors generated through VOCs are essential" (Facilities manager).

It was observed that experts considered the importance of complying with indoor air quality standards before approaching other sub-criteria.

The second sub-criterion, visual comfort, deals with illuminance level, glare, daylight, and many factors that are important to occupants' productivity and health (e.g., eyesight, headache, migraine, etc.). Further, building scoring schemes such as BREEAM, LEED, CASBEE, and SBTool have considered visual comfort as an important factor in their assessment schemes. Similarly, in light of the current study findings (refer to Figure 6c) it has obtained the second-highest value $(21.09 \%)$ among five indicators.

The third indicator, acoustic comfort (18.32\%) is the well-being and building occupants' experience of the acoustic environment. A building's capacity to create thermal comfort (14.71\%) appeared as the fourth most important indicator of SBs, according to Figure 6c. An engineer noted that

"Modern smart buildings must comprise with IoT devices with controllability with a mobile phone or personal computers according to needs of the occupants".

However, many experts (engineers, architects, and facilities managers) pointed out that in Sri Lanka these technologies are yet to be developed, and currently building environments are controlled by the main BMS. Therefore, the indicator smart appliances for personalized control appears at the fifth position $(13.11 \%)$ of the segment. Spatial comfort is the sixth indicator $(8.56 \%)$ since it is to be considered mostly during the design stage of a building. Hence, respondents noted that equal consideration could not be given as in the operation stage, yet, the importance cannot be ignored. 


\subsubsection{Energy Management}

As evident in Table 7 and Figure 6d, energy management formed the fourth most important criterion with a relative weight of $8.94 \%$. Experts in commercial buildings stated that energy management makes up the key criterion in many building scoring schemes adopted like green schemes. Research findings published by the energy analysis department of the University of California illustrates the importance of focusing on energyrelated functions of a commercial building. As shown in Figure 6d, smart metering has been ranked as the most significant criterion among the others, with a relative weight of $33.82 \%$. Experts representing facilities management, engineering, and building automation argued that this criterion is one of the most important in commercial buildings where building spaces are rented. An example of a quote includes:

"Smart metering as one of the most important criteria in commercial buildings as building spaces are rented for the external parties for commercial purposes, which mandates the requirement of accurate records and also smart metering provides the basis for energy monitoring and evaluation" (Facilities manager).

Energy storage has significant importance in a smart commercial building, indicating the second-highest relative importance with a relative weight of $24.46 \%$. Engineers in the field commented that "energy storage systems provide versatility to control buildings load and combine the demand with energy generation in the grid", which is agreed in a review carried by Kintner-Meyer et al. [67]. As presented in Figure 6d, intelligent control for energy management was ranked third based on the gained relative weight of $17.27 \%$.

Energy-saving measures and procedures implementation is the fourth weighted criterion according to Figure $6 \mathrm{~d}(14.04 \%)$. It includes passive design features of the building, implementation of best practices within the premises, tenant awareness, and so on. Adaptive energy management systems was placed as the fifth criterion, which has a relative weight of $0.1699 \%$. A facilities manager noted:

"This system is rare within Sri Lankan commercial buildings because it entails considerable investment and requires large spaces and hence, contribution to the building energy cost may depend on the payback period of the system".

\subsubsection{Occupants' Health and Safety}

Followed by energy management, the health and safety of the building occupants were ranked as the fifth most important criterion of smart commercial buildings as per Table 7 and Figure 6e. Assistance to people for health care (29.86\%), defined as a modern emergency response approach developed to address individual health problems and emergencies within the building premises with the help of IoT devices, was ranked first under health and safety criteria. An engineering expert pointed out security to be a key service for the protection of information, assets, and resources from intentional attacks through physical access control or physical intrusion detection. Upholding the argument, facilities managers specifically stated that

"Security and access controls act as a preventive measure against malicious emergencies".

With similar views generated from experts, the criteria were ranked second (24.63\%). As presented in Figure 6e, emergency response is the third subcriterion (17.17\%). Considering the vulnerabilities of a building and the relative severity of the impacts that could occur, an effective approach for response is mandatory to manage risk effectively. According to Figure 6e, movement detection $(14.71 \%)$ and weather prediction and disaster response (13.64\%) secured the last two ranks, respectively. A facilities management expert noted:

"Movement detection, weather prediction, and disaster response are two novel criteria to Sri Lanka requiring advanced technologies assimilating facial recognizing method with national information hubs and integrating building information with disaster management authorities respectively". 


\subsubsection{Sustainability Features}

Buildings have around $40 \%$ of global energy, $25 \%$ of global air, overall $40 \%$ of global resources, and produce about $1 / 3$ of GHG emissions, which are major barriers to the protection and preservation of resources. Moreover, facilities managers manifested that sustainable and green building concept is important in evaluating commercial buildings in Sri Lanka. Results of the data analysis (refer to Table 7 and Figure 6f) indicate that renewable energy sources have the most importance, with a relative weight of $32.57 \%$ in the sustainability criterion. An architect emphasized that

"Smart buildings must have the capability to employ renewable sources and generate its energy to fulfill its day-to-day requirements and it may create a self-sufficient building from energy".

Moreover, an engineering expert pointed out that

"Extra energy generated by the sources could be transmitted to the national grid through net metering and generate an extra income which is highly popular with solar photovoltaic cells and wind turbines".

However, the research carried out by Torcellini and Crawley [68] revealed that investing in renewable energy is more efficient and productive in achieving sustainability than investing in energy management systems (EMS) or BMS. While the study agrees on the necessity of renewable energy within the sustainability determinant, in order to achieve overall smartness, the necessity of BMS cannot be disregarded.

Figure $6 \mathrm{f}$ points out that having conservation techniques $(25.71 \%)$ is vital as the second most significant criterion. On a similar note, Cook, Sharma, and Gurung [69] state that implementation of water reusing approaches such as rainwater harvesting, separation of black water, and greywater use for gardening and flushing actions is important to the green segment of SBs. Material conservation evaluates the usage of non-hazardous, durable and degradable materials in the construction of the building. As evident in Figure 6f, experts positioned the criterion in third place $(16.5 \%)$. The fourth indicator $(13.25 \%)$ represents the proper utilization of land plots while designing the building. Clements-Croome [70] states that SBs should be high-rise buildings to take the maximum benefit from the available land and to minimize land wastage. Implementation of proper waste management approaches ( $3 \mathrm{R}$ concept) has the fifth significant score which is $11.98 \%$. It emphasizes that SBs should not only be focusing on minimizing building costs but on reducing physical waste too.

\subsection{Procedure in Implementing the Proposed Scoring Systems}

Figure 7 presents the framework for implementing the scoring system. Initially, an evaluator has to check whether the building meets the sub-criteria given in the scoring system (Table 7). If the building comprises the sub-criteria, a relevant score from Table 7 should be assigned (e.g., $\mathrm{A} 1=22.43 \%)$. Then, the performance score for the major criteria should be computed (e.g., automation $=(\mathrm{A} 1+\mathrm{A} 2+\mathrm{A} 3+\mathrm{A} 4+\mathrm{A} 5) \times \mathrm{A})$. Finally, the performance scores of all six main criteria should be added to derive the overall score of the building (e.g., $\mathrm{A}+\mathrm{B}+\mathrm{C}+\mathrm{D}+\mathrm{E}+\mathrm{F}$ ).

The final score provides an indication of the level of smartness of the building based on which decisions can be made regarding strategies to improve or maintain the smartness level. The evaluation should be a continuous process.

Compared with the scoring systems available to assess smartness, the presented approach through this study is novel due to key considerations. 2010/31/EU and 2012/27/EU Directives [8] promote the improvement of the energy performance of buildings within the European Union. It considers outdoor climatic and local conditions, as well as indoor climate requirements and cost effectiveness. This is enforceable within the European Union and the United Kingdom; hence, is currently not applicable to the Sri Lankan context. Further, its focus on energy management, health and safety, data communication of a building, occupancy comfort, and sustainability features are lower compared with the current scoring system developed by this study. The Honeywell Smart Building Score [9] 
measures fifteen smart assets in a building and rates them across three criteria: green, safe and productive. The scoring system focuses more on the green, safety, and productivity aspects of a building compared with the smartness or intelligent level of a building. The smartness of a building across literature remains a vague term that needs to be evaluated considering several criteria. Omar [10] attempts to define elements and dimensions characterizing intelligent buildings by examining the existing literature. However, the framework does not comprise a scoring system, rather, it comprises a list of factors defining intelligent buildings. Jain [7] attempted to develop a set of criteria to evaluate the level of smartness of buildings. This study comprises more areas than other scoring systems and seems to be a more successful scoring system. The tool developed as a part of the study includes the evaluation of 6 core systems and services, including a total of 39 subservices and 7 ICT-based systems and services, including 51 subservices. However, the study does not provide a detailed look into aspects such as health and safety, energy management, and indoor environmental quality. The scoring system developed by this study is not confined to particular systems but provides an overall solution applicable to a building as a whole.

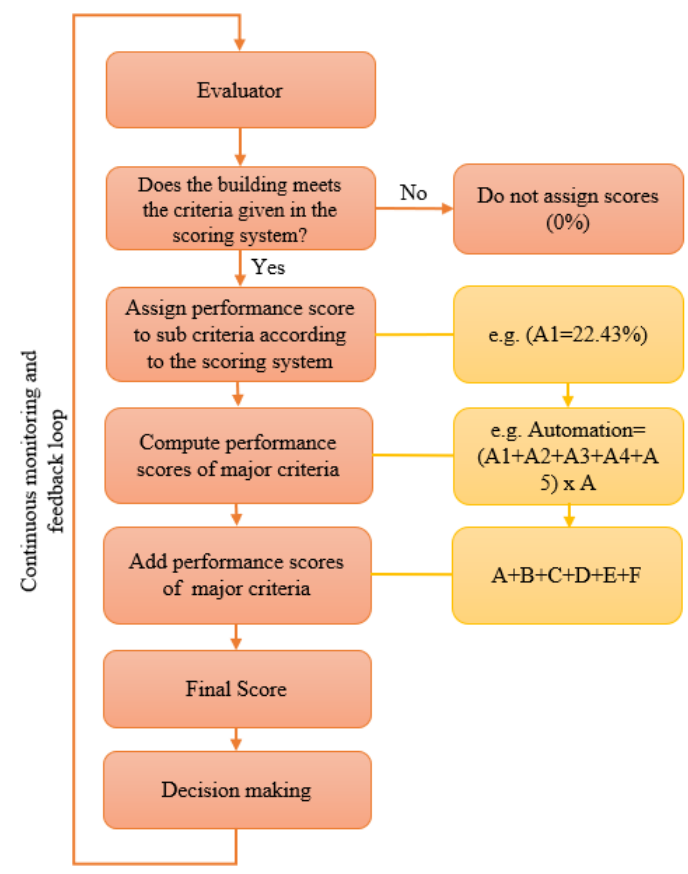

Figure 7. Framework for implementing the scoring system.

\section{Conclusions and Recommendations}

The purpose of this study was to develop a scoring system that would assist in evaluating the smartness level of commercial buildings. The study revealed the existence of six distinctive criteria for this purpose: automation, communication and data sharing, occupants' comfort, energy management, occupants' health and safety, and sustainability. The automation criterion with the highest score was suggested to be the dominant criterion $(45.59 \%)$. Communication and data sharing followed thereafter with a score of $18.76 \%$, indicating the importance given by the study findings in establishing the backbone of SB. Occupant comfort was ranked as the third criterion which indicates the necessity of focusing on the ultimate goal of a smart commercial building, which is to ensure occupants' comfort. The analysis shows that energy management, occupants' health and safety, and sustainability features received fourth, fifth, and sixth positions within the scoring system. This indicates the prominence given to all the criteria that lead to creating a SB. The results of the research can be used in the following ways to illuminate theory and practice.

The research has a well-defined the criteria to evaluate the smartness of commercial buildings with a scoring system. Most importantly, this identification of criteria is a vital 
achievement as there was a gap in Sri Lanka data that needed to be addressed. The scoring system developed by the study looks into various functions and dimensions of the built environment, thereby complementing the existing studies confined to a specific category such as mechanical and electrical systems. Further, the study outlines a few simple steps that ought to be followed during the usage of the scoring system. This process acts as a platform for continuous monitoring of key building features and encourages the development of building features to meet smartness scores. Moreover, prioritizing the smart criteria and sub-criteria is a noteworthy output gained from the study as there is a lack of such a hierarchy in the smart commercial building sector. Hence, the study addressed a current knowledge gap and complements the existing studies by presenting a scoring system. The scoring system comprises a well-defined criterion to evaluate the level of smartness of Sri Lankan commercial buildings.

Outcomes of this research will be beneficial for industry practitioners in the building industry for the improvement of smart features. The developed criteria and scoring method is a guideline for professionals in the construction industry to focus and deliver SBs that meet the major criteria of smartness. The study further provides an opportunity to satisfy smart criteria from the design stage of the building, thereby overcoming complexities met in converting traditional buildings to smart. Further, an opportunity to enhance organization goodwill by recognizing the smart score level achieved by each organization is one of the highest contributions made to the industry by the study. Furthermore, the developed scheme can be used as a standard to elaborate the current level of smartness of commercial buildings in Sri Lanka and thereby attract new overseas customers and investors.

The study was limited to analysis of the smart characteristics of commercial buildings in Sri Lanka. Hence, a potential research avenue would be to expand the scope of smart features to other types of sectors to evaluate and rate the facilities. Moreover, it is recommended to further develop the current assessment criteria up to a star grading system for commercial buildings. Some further thoughts to stimulate research in the field of smart building are as follows.

Human biological systems have evolved over centuries based on environmental changes. Similarly, intelligent systems need to be integrated within smart buildings to ensure evolution with occupants' feedback through volunteered geographic information or other crowdsourcing strategies. Future studies can address additional challenges by integrating the building evolution process efficiently and accurately at the city level. A smart city digital twin might be a potential solution to develop a connected network of smart buildings to visualize the accumulated data collected from different buildings. This solution would provide an information-rich database for decision makers at the city scale. However, efforts in developing smart city digital twins are at a conceptual level. Moreover, there is a lack of metrics or criteria for evaluating the smartness of cities. An example of a work-in-progress digital twin of a city is Virtual Singapore, which is a three-dimensional (3D) city model and data platform. This calls for researchers in the smart building domain to look at the growing worldwide trends and develop solutions that would lead to smart buildings being integrated with city digital twins.

Author Contributions: Conceptualization, R.N.G.; methodology, R.N.G.; validation, R.N.G. and F.N.A.; formal analysis, R.N.G. and F.N.A.; investigation, R.N.G. and F.N.A.; resources, R.N.G. and F.N.A.; data curation, F.N.A.; writing-original draft preparation, F.N.A.; writing-review and editing, R.N.G., F.N.A. and S.M.E.S.; visualization, F.N.A.; supervision, S.M.E.S.; project administration, F.N.A. All authors have read and agreed to the published version of the manuscript.

Funding: No funding was received.

Data Availability Statement: The data presented in this study are available on request from the corresponding author. The data are not publicly available as the data contain confidential information which cannot be publicly disclosed.

Conflicts of Interest: The authors declare no conflict of interest. 


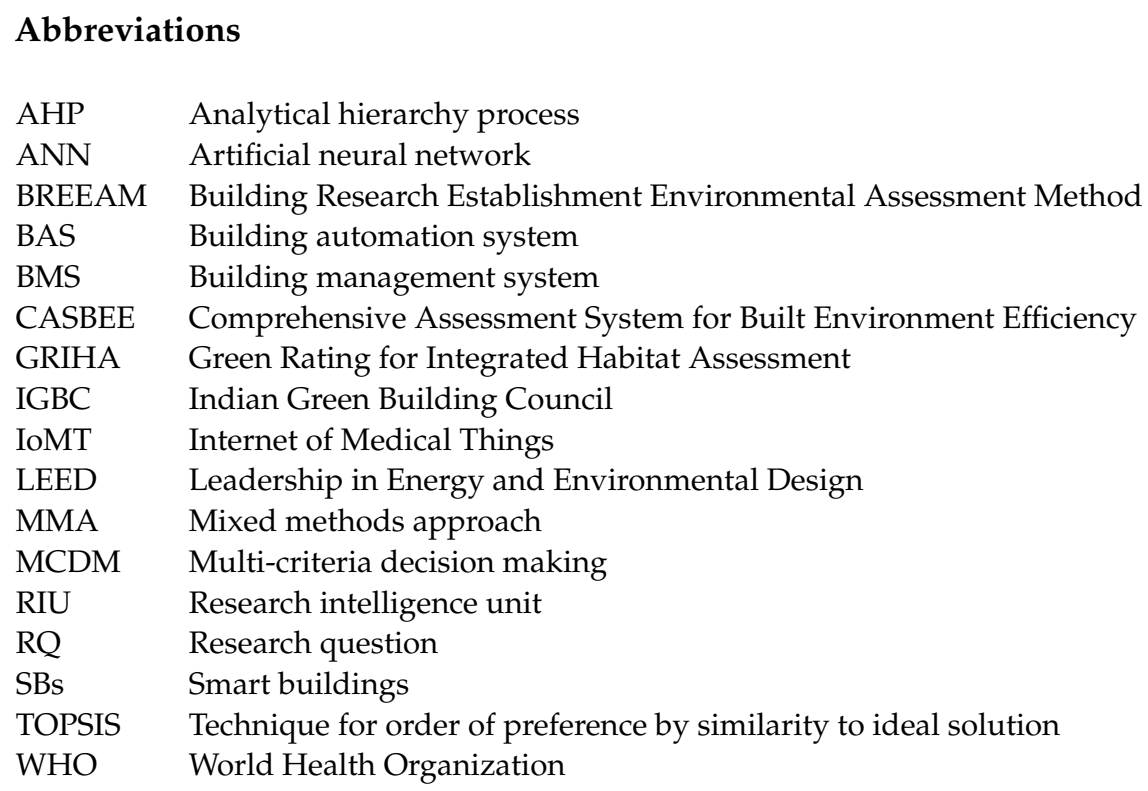

\section{References}

1. Statista Research Department. Statista. 2021. Available online: https://www.statista.com/statistics/1189630/commercial-realestate-market-size-global/ (accessed on 10 November 2021).

2. Lugoda, U. How COVID-19 Will Change Commercial Real Estate. The Sunday Morning. 2020. Available online: https: / / www.themorning.lk/how-covid-19-will-change-commercial-real-estate/ (accessed on 13 November 2021).

3. Marcotorchino, R. IoT Blog What Is a Smart Commercial Building? Sierra Wireless. Available online: https://www.sierrawireless. com/iot-blog/what-is-a-smart-commercial-building/ (accessed on 13 November 2021).

4. Andriy. Smart Buildings_A Hot Trend in Commercial Real Estate-Vakoms Blog. 2019. Available online: https://blog.vakoms com/smart-buildings-a-hot-trend-in-commercial-real-estate/ (accessed on 2 October 2021).

5. Froufe, M.M.; Chinelli, C.K.; Guedes, A.L.A.; Haddad, A.N.; Hammad, A.W.A.; Soares, C.A.P. Smart buildings: Systems and drivers. Buildings 2020, 10, 153. [CrossRef]

6. Apanaviciene, R.; Vanagas, A.; Fokaides, P.A. Smart building integration into a smart city (SBISC): Development of a new evaluation framework. Energies 2020, 13, 2190. [CrossRef]

7. Jain, K. Development of a Smart Building Evaluation System for Office Buildings; Technische Universitat Berlin: Berlin, Germany, 2019. [CrossRef]

8. Directive 2010/31/EU and Directive 2012/27/EU. Discussion Document-Definition and Calculation Methodology of the Smart Readiness Indicator; 2019; pp. 1-15. Available online: https://webgate.ec.europa.eu/regdel/web/meetings/1462/documents/3895 (accessed on 10 September 2021).

9. Honeywell International Inc. Honeywell Smart Building Score (HSBS). 2017. Available online: http:/ / smartbuildings.honeywell. com/hsbs_concept (accessed on 2 September 2021).

10. Omar, O. Intelligent building, definitions, factors and evaluation criteria of selection. Alex. Eng. J. 2018, 57, 2903-2910. [CrossRef]

11. Wu, Z.; Li, H.; Feng, Y.; Luo, X.; Chen, Q. Developing a green building evaluation standard for interior decoration: A case study of China. Build. Environ. 2019, 152, 50-58. [CrossRef]

12. Wang, Z.; Wang, L.; Dounis, A.; Yang, R. Multi-agent control system with information fusion. Appl. Energy 2012, 99, 247-254 [CrossRef]

13. Carter, S.; Mankoff, J. Prototypes in the wild lessons from three ubicomp systems. IEEE Pervasive Comput. 2005, 4, 51-57. [CrossRef]

14. Varma, C.R.S.; Palaniappan, S. Comparision of green building rating schemes used in North America, Europe and Asia. Habitat Int. 2019, 89, 101989. [CrossRef]

15. Costa, C.; Figueiredo, R.; Silva, V.; Bazzurro, P. Application of open tools and datasets to probabilistic modeling of road traffic disruptions due to earthquake damage. Earthq. Eng. Struct. Dyn. 2020, 49, 1236-1255. [CrossRef]

16. Harirchian, E.; Hosseini, S.E.A.; Jadhav, K.; Kumari, V.; Rasulzade, S.; Işık, E.; Wasif, M.; Lahmer, T. A review on application of soft computing techniques for the rapid visual safety evaluation and damage classification of existing buildings. J. Build. Eng. 2021, 43, 102536. [CrossRef]

17. Harirchian, E.; Jadhav, K.; Kumari, V.; Lahmer, T. ML-EHSAPP: A prototype for machine learning-based earthquake hazard safety assessment of structures by using a smartphone app. Eur. J. Environ. Civ. Eng. 2021, 26, 1-21. [CrossRef]

18. Harirchian, E.; Jadhav, K.; Mohammad, K.; Aghakouchaki Hosseini, S.E.; Lahmer, T. A comparative study of MCDM methods integrated with rapid visual seismic vulnerability assessment of existing RC structures. Appl. Sci. 2020, 10, 6411. [CrossRef] 
19. Alam, N.; Alam, M.S.; Tesfamariam, S. Buildings' seismic vulnerability assessment methods: A comparative study. Nat. Hazards 2012, 62, 405-424. [CrossRef]

20. Sepasgozar, S.M.; Ghobadi, M.; Shirowzhan, S.; Edwards, D.J.; Delzendeh, E. Metrics Development and Modelling the Mixed Reality and Digital Twin Adoption in the Context of Industry 4.0. Eng. Constr. Archit. Manag. 2021, 28, 1355-1376. [CrossRef]

21. Serrano, W. iBuilding: Artificial intelligence in intelligent buildings. Neural Comput. Appl. 2021, 1-23. [CrossRef]

22. Cardone, G.; Foschini, L.; Bellavista, P.; Corradi, A.; Borcea, C.; Talasila, M.; Curtmola, R. Fostering participaction in smart cities: A geo-social crowdsensing platform. IEEE Commun. Mag. 2013, 51, 112-119. [CrossRef]

23. Morvaj, B.; Lugaric, L.; Krajcar, S. Demonstrating smart buildings and smart grid features in a smart energy city. In Proceedings of the 2011 3rd International Youth Conference on Energetics (IYCE), Leiria, Portugal, 7-9 July 2011; pp. 1-8.

24. Fisco, N.R.; Adeli, H. Smart structures: Part I-Active and semi-active control. Sci. Iran. 2011, 18, 257-284. [CrossRef]

25. Hollands, R.G. Will the real smart city please stand up? Intelligent, progressive or entrepreneurial? City 2008, 12, 303-320. [CrossRef]

26. Everett, R. The 'building colleges for the future' program. Delivering a green and ntelligent building agenda. New Rev. Inf. Netw. 2008, 14, 3-20. [CrossRef]

27. Batov, E.I. The distinctive features of "smart" buildings. Procedia Eng. 2015, 111, 103-107. [CrossRef]

28. Bellavista, P.; Cardone, G.; Corradi, A.; Foschini, L. Convergence of MANET and WSN in IoT urban scenarios. IEEE Sens. J. 2013, 13, 3558-3567. [CrossRef]

29. Nguyen, T.A.; Aiello, M. Energy intelligent buildings based on user activity: A survey. Energy Build. 2013, 56, 244-257. [CrossRef]

30. Pérez, G.; Coma, J.; Martorell, I.; Cabeza, L.F. Vertical Greenery Systems (VGS) for energy saving in buildings: A review. Renew. Sustain. Energy Rev. 2014, 39, 139-165. [CrossRef]

31. Mbungu, N.T.; Bansal, R.C.; Naidoo, R.M.; Bettayeb, M.; Siti, M.W.; Bipath, M. A dynamic energy management system using smart metering. Appl. Energy 2020, 280, 115990. [CrossRef]

32. Aslam, S.; Iqbal, Z.; Javaid, N.; Khan, Z.A.; Aurangzeb, K.; Haider, S.I. Towards efficient energy management of smart buildings exploiting heuristic optimization with real time and critical peak pricing schemes. Energies 2017, 10, 2065. [CrossRef]

33. Catarinucci, L.; de Donno, D.; Mainetti, L.; Palano, L.; Patrono, L.; Stefanizzi, M.; Tarricone, L. An IoT-aware architecture for smart healthcare systems. IEEE Internet Things J. 2015, 2, 515-526. [CrossRef]

34. Pozo, A.; Alonso, Á.; Salvachúa, J. Evaluation of an IoT Application-Scoped Access Control Model over a Publish/Subscribe Architecture Based on FIWARE. Sensors 2020, 20, 4341. [CrossRef]

35. Lin, C.-Y.; Chu, E.T.-H.; Ku, L.-W.; Liu, J.W.S. Active disaster response system for a smart building. Sensors 2014, 14, 17451-17470 [CrossRef]

36. Yun, J.; Lee, S.-S. Human movement detection and identification using pyroelectric infrared sensors. Sensors 2014, 14, 8057-8081. [CrossRef]

37. Amin, U.; Hossain, M.J.; Lu, J.; Fernandez, E. Performance analysis of an experimental smart building: Expectations and outcomes. Energy 2017, 135, 740-753. [CrossRef]

38. Khantong, S.; Ahmad, M.N. An ontology for sharing and managing information in disaster response: In flood response usage scenarios. J. Data Semant. 2020, 9, 39-52. [CrossRef]

39. Wijesinghe, L.; Siriwardena, P.; Wijeratne, S.; Purasinghe, H.; Dias, D. Disaster and emergency warning network (DEWN): Harnessing cellular technologies for early warning dissemination. In Proceedings of the 2011 IEEE Global Humanitarian Technology Conference, Seattle, WA, USA, 30 October-1 November 2011; IEEE: Piscataway, NJ, USA, 2011 ; pp. 476-480.

40. Lawrence, T.M.; Boudreau, M.-C.; Helsen, L.; Henze, G.; Mohammadpour, J.; Noonan, D.; Patteeuw, D.; Pless, S.; Watson, R.T. Ten questions concerning integrating smart buildings into the smart grid. Build. Environ. 2016, 108, 273-283. [CrossRef]

41. Elhakeem, A.; Hegazy, T. Building asset management with deficiency tracking and integrated life cycle optimisation. Struct. Infrastruct. Eng. 2012, 8, 729-738. [CrossRef]

42. Eini, R.; Linkous, L.; Zohrabi, N.; Abdelwahed, S. Smart building management system: Performance specifications and design requirements. J. Build. Eng. 2021, 39, 102222. [CrossRef]

43. Dey, M.; Rana, S.P.; Dudley, S. A case study based approach for remote fault detection using multi-level machine learning in a smart building. Smart Cities 2020, 3, 401-419. [CrossRef]

44. Akadiri, P.O.; Chinyio, E.A.; Olomolaiye, P.O. Design of a sustainable building: A conceptual framework for implementing sustainability in the building sector. Buildings 2012, 2, 126-152. [CrossRef]

45. Lazarova-Molnar, S.; Mohamed, N. Collaborative data analytics for smart buildings: Opportunities and models. Clust. Comput. 2019, 22, 1065-1077. [CrossRef]

46. Sembroiz, D.; Ricciardi, S.; Careglio, D. A novel cloud-based IoT architecture for smart building automation. In Security and Resilience in Intelligent Data-Centric Systems and Communication Networks; Elsevier: Amsterdam, The Netherlands, 2018; pp. 215-233.

47. Le, D.N.; Le Tuan, L.; Tuan, M.N.D. Smart-building management system: An Internet-of-Things (IoT) application business model in Vietnam. Technol. Forecast. Soc. Chang. 2019, 141, 22-35. [CrossRef]

48. Havard, N.; McGrath, S.; Flanagan, C.; MacNamee, C. Smart building based on Internet of Things technology. In Proceedings of the 2018 12th International Conference on Sensing Technology (ICST), Limerick, Ireland, 4-6 December 2018; IEEE: Piscataway, NJ, USA, 2018; pp. 278-281. 
49. Benavente-Peces, C. On the energy efficiency in the next generation of smart buildings-Supporting technologies and techniques. Energies 2019, 12, 4399. [CrossRef]

50. Behzadi, A.; Arabkoohsar, A.; Yang, Y. Optimization and dynamic techno-economic analysis of a novel PVT-based smart building energy system. Appl. Therm. Eng. 2020, 181, 115926. [CrossRef]

51. Ho, H.-C.; Puika, K.S.; Kasih, T.P. Development of IoT-based water reduction system for improving clean water conservation. Prz. Nauk. Inż. Ksztatt. Sr. 2020, 29, 54-61. [CrossRef]

52. Amoeda, R. Conservation of Materials Resources by Buildings Reuse and on Site Materials Reuse Strategies. En Congreso Internacional de Costrucción Sostenible y Soluciones Ecoeficientes; Universidad de Sevilla: Sevilla, Spain, 2015; pp. 983-994.

53. Dryjanski, M.; Buczkowski, M.; Ould-Cheikh-Mouhamedou, Y.; Kliks, A. Adoption of smart cities with a practical smart building implementation. IEEE Internet Things Mag. 2020, 3, 58-63. [CrossRef]

54. Jackson, J. Promoting energy efficiency investments with risk management decision tools. Energy Policy 2010, 38, 3865-3873. [CrossRef]

55. Kankhva, V. Risk management in the implementation of smart building projects. MATEC Web Conf. EDP Sci. 2017, 106, 08027. [CrossRef]

56. Daissaoui, A.; Boulmakoul, A.; Karim, L.; Lbath, A. IoT and big data analytics for smart buildings: A survey. Procedia Comput. Sci. 2020, 170, 161-168. [CrossRef]

57. Dounis, A.I.; Caraiscos, C. Advanced control systems engineering for energy and comfort management in a building environmentA review. Renew. Sustain. Energy Rev. 2009, 13, 1246-1261. [CrossRef]

58. Molnar, S.L.; Mohamed, N. A Framework for Collaborative Cloud-Based Fault Detection and Diagnosis in Smart Buildings. In Proceedings of the 7th International Conference on Modeling, Simulation, and Applied Optimization (ICMSAO), Sharjah, United Arab Emirates, 4-6 April 2017.

59. Herrera, N.R. In-situ and mixed-design interventions. In Living Labs; Springer: Berlin/Heidelberg, Germany, 2017 ; pp. 157-167.

60. Etikan, I.; Musa, S.A.; Alkassim, R.S. Comparison of convenience sampling and purposive sampling. Am. J. Theor. Appl. Stat. 2016, 5, 1-4. [CrossRef]

61. Oxford Business Group. Developers in Sri Lanka Meet High Demand for High-End Office Space. Available online: https: / / oxfordbusinessgroup.com/analysis/making-grade-developers-are-meeting-demand-high-end-office-space (accessed on 13 June 2021).

62. Stanković, M.; Gladović, P.; Popović, V. Determining the importance of the criteria of traffic accessibility using fuzzy AHP and rough AHP method. Decis. Mak. Appl. Manag. Eng. 2019, 2, 86-104. [CrossRef]

63. Saaty, T.L. Resolution of retributive conflicts. IFAC Proc. Vol. 1986, 19, 91-94. [CrossRef]

64. Wong, J.K.W.; Li, H. Application of the analytic hierarchy process (AHP) in multi-criteria analysis of the selection of intelligent building systems. Build. Environ. 2008, 43, 108-125. [CrossRef]

65. Deng, X.; Hu, Y.; Deng, Y.; Mahadevan, S. Supplier selection using AHP methodology extended by D numbers. Expert Syst. Appl. 2014, 41, 156-167. [CrossRef]

66. Kastner, W.; Kofler, M.; Jung, M.; Gridling, G.; Weidinger, J. Building Automation Systems Integration into the Internet of Things the IoT6 approach, its realization and validation. In Proceedings of the 2014 IEEE Emerging Technology and Factory Automation (ETFA), Barcelona, Spain, 16-19 September 2014; IEEE: Piscataway, NJ, USA, 2014; pp. 1-9.

67. Kintner-Meyer, M.C.; Molburg, J.C.; Subbarao, K.; Kumar, N.P.; Bandyopadhyay, G.; Finley, C.; Florita, A.R.; Brackney, L. The role of energy storage in commercial building: A preliminary report. Pac. Northwest Natl. Lab. Richland Washington. 2010, 1-102. Available online: https://www.pnnl.gov/main/publications/external/technical_reports/pnnl-19853.pdf (accessed on 1 July 2021).

68. Torcellini, P.A.; Crawley, D.B. Understanding zero-energy buildings. ASHRAE J. 2006, 48, 62-69.

69. Cook, S.; Sharma, A.K.; Gurung, T.R. Evaluation of alternative water sources for commercial buildings: A case study in Brisbane, Australia. Resour. Conserv. Recycl. 2014, 89, 86-93. [CrossRef]

70. Clements-Croome, D. Sustainable intelligent buildings for people: A review. Intell. Build. Int. 2011, 3, 67-86. 